\title{
Uranium-series comminution ages of continental sediments: Case study of a Pleistocene alluvial fan
}

\author{
Victoria E. Lee $^{\text {a, } 1^{*}}$, Donald J. DePaolo ${ }^{a, b}$, John N. Christensen ${ }^{\text {b }}$ \\ ${ }^{a}$ Dept. of Earth \& Planetary Science, University of California, Berkeley, 307 McCone Hall, Berkeley, CA 94720- \\ 4767 USA \\ ${ }^{b}$ Earth Sciences Division, Lawrence Berkeley National Laboratory, 1 Cyclotron Rd., MS 70A4418, Berkeley, CA \\ 94720 USA \\ * Corresponding author Tel.: +44 (0)1865 272969; Fax: +44 (0)1865 272072 \\ ${ }^{1}$ current address: Dept. of Earth Sciences, University of Oxford, Parks Road, Oxford, OX1 3PR, United Kingdom \\ email addresses: victoria.lee@earth.ox.ac.uk (V.E. Lee), depaolo@eps.berkeley.edu (D.J. DePaolo), \\ JNChristensen@lbl.gov (J.N. Christensen)
}

\section{Abstract}

3 Obtaining quantitative information about the timescales associated with sediment transport,

4 storage, and deposition in continental settings is important but challenging. The uranium-series

5 comminution age method potentially provides a universal approach for direct dating of

6 Quaternary detrital sediments, and can also provide estimates of the sediment transport and

7 storage timescales. (The word "comminution" means "to reduce to powder," reflecting the start

8 of the comminution age clock as reduction of lithic parent material below a critical grain size

9 threshold of $\sim 50 \mu \mathrm{m}$.) To test the comminution age method as a means to date continental

10 sediments, we applied the method to drill-core samples of the glacially-derived Kings River Fan

11 alluvial deposits in central California. Sediments from the $45 \mathrm{~m}$ core have independently-

12 estimated depositional ages of up to $\sim 800 \mathrm{ka}$, based on paleomagnetism and correlations to

13 nearby dated sediments. We characterized sequentially-leached core samples (both bulk

14 sediment and grain size separates) for $\mathrm{U}, \mathrm{Nd}$, and $\mathrm{Sr}$ isotopes, grain size, surface texture, and

15 mineralogy. In accordance with the comminution age model, where ${ }^{234} \mathrm{U}$ is partially lost from

16 small $(<50 \mu \mathrm{m})$ sediment grains due to alpha recoil, we found that $\left({ }^{234} \mathrm{U} /{ }^{238} \mathrm{U}\right)$ activity ratios 
17 generally decrease with age, depth, and specific surface area, with depletions of up to $9 \%$ relative

18 to radioactive equilibrium. The resulting calculated comminution ages are reasonable, although

19 they do not exactly match age estimates from previous studies and also depend on assumptions

20 about ${ }^{234} \mathrm{U}$ loss rates. The results indicate that the method may be a significant addition to the

21 sparse set of available tools for dating detrital continental sediments, following further

22 refinement. Improving the accuracy of the method requires more advanced models or

23 measurements for both the recoil loss factor $f_{\alpha}$ and weathering effects. We discuss several

24 independent methods for obtaining $f_{\alpha}$ on individual samples that may be useful for future studies.

Keywords: isotope geochemistry; U-series isotopes; sediment; geochronology; Quaternary;

Sierra Nevada 


\section{Introduction}

The lifetimes of clastic sediment particles in continental settings - from initial formation by weathering and erosion, to transport, storage, deposition, and lithification - both reflect and control the nature of geologic processes in the Earth's surface environment. Among the interrelated areas of interest in which the timing, rates, and durations of sedimentary processes play a key role are: understanding mechanisms of landscape evolution (Dietrich et al., 1982; Dietrich et al. 2003); modulating elemental cycles by controlling the residence time of sediments

34 in natural reservoirs such as floodplains (Dunne et al., 1998, and refs. therein); formation and 35 interpretation of depositional records of paleoclimate and tectonic activity (e.g., Phillips et al., 1997; Last and Smol, 2001; Molnar, 2004); influencing the long-term, erosion-driven drawdown

37 of atmospheric $\mathrm{CO}_{2}$ by silicate weathering (Raymo and Ruddiman, 1992); and determining 38 sediment flux to the oceans (Hay, 1998; Syvitski et al., 2003).

Although quantifying the timescales of sedimentary cycling is important, obtaining this information is difficult, especially over geologic timescales where direct observation is not

41 possible. Uranium-series isotopes may be helpful in this regard. The isotopic fractionation 42 between various nuclides of the uranium-series decay chains can be used to provide information

43 about sediment history, behavior, and weathering over time periods up to $\sim 10^{6}$ yrs (e.g., Osmond 44 and Ivanovich, 1992; Vigier et al., 2001; Chabaux et al., 2003; Granet et al., 2007; Dosseto et al., 45 2008). In particular, the uranium-series comminution age method (DePaolo et al., 2006) may 46 provide a way to directly date detrital Quaternary sediments and yield information about the 47 timescales of sedimentary processes (Figure 1). (The word "comminution" means "to reduce to 48 powder," and refers to the start of the U isotope age clock when bedrock has been reduced by 
49 weathering and erosion below a critical grain size threshold to form silt- and clay-sized detrital 50 particles.)

This study evaluates whether the comminution age method, previously applied to well-

52 sorted marine sediments (DePaolo et al., 2006), has applicability to the more challenging case of

53 poorly-sorted continental sediments. Continental sediments are often not suitable for dating by

54 other methods (e.g., cosmogenic radionuclide dating, biostratigraphy, and chemostratigraphy),

55 and may have uranium-hosting nondetrital phases that could perturb the comminution age

56 method as well. We measured uranium isotopes and other characteristics of alluvial fan

57 sediments having independently-estimated depositional ages. Sample pretreatment methods for

58 sequential leaching and sieving were also developed, applied, and evaluated.

\section{2. Comminution age method}

The comminution age model (DePaolo et al., 2006) is based on the loss of ${ }^{234} \mathrm{U}$ from a

64 sediment particle due to alpha recoil following decay of the ${ }^{238} \mathrm{U}$ parent (Kigoshi, 1971). In the

$65{ }^{238} \mathrm{U}$ decay series, this recoil loss occurs via the alpha decay of ${ }^{238} \mathrm{U}$ to an intermediate short-

66 lived ${ }^{234} \mathrm{Th}$, which then rapidly undergoes beta decay (without significant recoil) to ${ }^{234} \mathrm{U}$. The

$67{ }^{234} \mathrm{Th}$ precursor to ${ }^{234} \mathrm{U}$ is recoiled an average distance of $\sim 34 \mathrm{~nm}$ in typical silicate minerals (Sun

68 and Semkow, 1998; Maher et al., 2006), a distance that varies only a few nm due to straggling

69 and variations in the compositions (density) of common crustal minerals (Hashimoto et al.,

70 1985). For grains smaller than a threshold diameter of $\sim 50 \mu \mathrm{m}$, recoil loss of ${ }^{234} \mathrm{U}$ results in a

71 measurable decrease in $\left({ }^{234} \mathrm{U} /{ }^{238} \mathrm{U}\right.$ ). (Parentheses denote the activity ratio, the ${ }^{234} \mathrm{U} /{ }^{238} \mathrm{U}$ isotope 
72 ratio normalized by the ${ }^{234} \mathrm{U} /{ }^{238} \mathrm{U}$ ratio of a standard in secular, or radioactive, equilibrium.)

73 Therefore, if alpha recoil is the only process that separates ${ }^{234} \mathrm{U}$ from ${ }^{238} \mathrm{U}$, the measured

$74\left({ }^{234} \mathrm{U} /{ }^{238} \mathrm{U}\right)$ ratio of a sediment grain, $A_{\text {meas }}$, is a function of four parameters related by the

75 following expression:

$\left.77 \quad A_{\text {meas }}=\left(1-f_{\alpha}\right)+\left[A_{0}-\left(1-f_{\alpha}\right)\right]\right]^{-\lambda_{234} t_{\text {coum }}}$

79 where $t_{\text {comm }}$ is the amount of time elapsed since the grain became smaller than the threshold size,

80 referred to as the comminution age, $f_{\alpha}$ is the fraction of ${ }^{238} \mathrm{U}$ decays that result in direct recoil

81 loss of the ${ }^{234} \mathrm{U}$ daughter ( $f_{\alpha}$ thus should be correlated with the grain surface area and size), $\lambda_{234}$

82 is the ${ }^{234} \mathrm{U}$ decay constant $\left(\lambda_{234}=2.82629 \times 10^{-6} \mathrm{yr}^{-1}\right)$, and $A_{0}$ is the $\left({ }^{234} \mathrm{U} /{ }^{238} \mathrm{U}\right)$ of the parent

83 material from which the sediment grains are derived. $A_{o}$ is commonly assumed to be the secular

84 equilibrium value $\left({ }^{234} \mathrm{U} /{ }^{238} \mathrm{U}\right)=1$ for nonporous, crystalline rocks. This method of determining a

85 comminution age is limited to ages less than $\sim 1 \mathrm{Ma}$, since $A_{\text {meas }}$ will reach a grain-size-dependent

86 steady state value after about four half lives of ${ }^{234} \mathrm{U}$.

87 The uranium-series comminution age dating method differs from many existing methods

88 for dating continental detrital sediment deposits in that it is a direct dating method with minimal

89 restrictions on material requirements, and the comminution age contains information about not

90 just depositional age, but also transport + storage timescales. The only theoretical requirement

91 for comminution age dating, a uranium-bearing fine-grained sediment component, is easily

92 fulfilled for most lithologic compositions and deposit types. Other dating methods are generally

93 limited by requirements for specific types and/or quantities of material that may not be

94 universally present in the sediment. Examples include nondetrital materials such as organic 
95 matter $\left({ }^{14} \mathrm{C}\right.$ dating), fossils (biostratigraphy), volcanic marker units (K-Ar and $\mathrm{Ar}-\mathrm{Ar}$ dating), and

96 select authigenic phases such as carbonate (U-series and stable isotope dating), as well as detrital

97 matter: large quantities of quartz (cosmogenic radionuclide (CRN) techniques, e.g., ${ }^{26} \mathrm{Al} /{ }^{10} \mathrm{Be}$

98 burial dating and ${ }^{10} \mathrm{Be}$ exposure dating (Gosse and Phillips, 2001)), and quartz or feldspar

99 (optically stimulated luminescence (OSL) dating (Aitken, 1998)). Nondetrital dating methods

100 generally yield only the depositional age. Detrital sediment ages obtained by CRN and OSL

101 dating methods should provide complementary information to comminution ages, taking into

102 account fundamental differences in what age is being recorded in the sediments (given the

103 different underlying physico-chemical mechanisms that produce age signals for each method), as

104 well as potential dissimilarities in the histories of the different grain size or mineral fractions

105 being dated.

106

107

108 3. Study area: Kings River Fan

109

There are several reasons why the Kings River Fan (KRF) was selected as a study area to

111 test the comminution age method on continental sediments. First, the expected comminution

112 ages can be figured out - there are independent constraints on depositional age, sediment

113 transport + storage times can be treated as negligible, and sediment production by glacial erosion

114 implies rapid particle formation and thus a well-defined start to the comminution age clock.

115 Second, the parent lithology is largely crystalline, allowing the assumption of $A_{0}=1$ to hold.

116 Third, the potential complicating effects of subaerial weathering on $\mathrm{U}$ isotope behavior are

117 minimal for the samples studied. 
119 the Sierra Nevada in central California (Figure 2). Sediment in this fan derives from a catchment

120 with an area of $4400 \mathrm{~km}^{2}$ (Weissmann et al., 2005), which is underlain almost entirely by

121 crystalline rocks of the Sierra Nevada batholith and related pre-intrusive metamorphic rocks.

122 Approximately the upper half of the basin was covered with ice during peak Pleistocene

123 glaciations (Wahrhaftig and Birman, 1965). In this glaciated area, where erosion was probably

124 most rapid, the bedrock is predominantly granitic.

125 Samples used in this study are from a $45 \mathrm{~m}$-long sediment core taken near the present-day

126 fan apex $\left(36^{\circ} 42^{\prime} 58^{\prime}\right.$ N, $119^{\circ} 38^{\prime} 53^{\prime}$ W). This is designated as Core B5 in Burow et al. (1999)

127 and Weissmann et al. (2002). Three depositional facies can be identified: channel deposits, 128 overbank deposits, and moderately mature paleosols (Figure 3a), all composed of glacial flour 129 and coarser sediment originating from Pleistocene glaciations in the Sierra Nevada (Weissmann 130 et al., 2002, and refs. therein).

131 Inferred depositional ages of the sediments in the KRF core as a function of depth are

132 shown in Figure 3b. The deepest samples have the most well-constrained ages: paleomagnetic 133 measurements on the core samples indicate that the Matuyama-Brunhes magnetic reversal (780 $134 \mathrm{ka}$ ) occurs near $41 \mathrm{~m}$ depth (Weissmann et al., 2002). Additional age information is obtained by 135 correlation to type sections described in Marchant and Allwardt (1981) using the age inferences 136 of Lettis (1988), which comprise the commonly-accepted chronology for the fan deposits of the 137 eastern San Joaquin Valley. The age-depth model includes temporal hiatuses between major 138 depositional units, corresponding to an episodic model of fan formation in which Sierra Nevada 139 glaciations caused aggradation of glacigenic sediment, and interglacial times correspond to 140 negligibly small deposition rates and the resultant formation of capping soils (Marchand, 1977; 
141 Huntington, 1980; Marchand and Allwardt, 1981; Lettis,1988; Weissmann et al., 2002). The

142 Upper-Middle Riverbank Formation is usually associated with marine isotope stages (MIS) 6 and

1438 (ca. 130 - $280 \mathrm{ka}$ ), the Upper Turlock Formation with MIS 16 and/or 18 (ca. 650 - $740 \mathrm{ka}$ ),

144 and the Lower Turlock Formation with MIS 20. The age constraints on the Turlock Lake units

145 in particular rely on the $615 \mathrm{ka}$ age of the Friant Pumice marker bed (Janda, 1965; Lettis 1988),

146 but more recent dating of constituent pumice clasts produce ages that vary widely, so the Friant

147 Pumice unit may not be as useful for chronostratigraphic control as originally thought (Sarna-

148 Wojcicki et al., 2000). Thus, there is uncertainty in the detailed age-depth profile of the KRF

149 deposits, but we believe the presence of the Matuyama-Brunhes magnetic reversal is a reliable

150 indication that the core sediments at 40-45 m depth have ages near $800 \mathrm{kyr}$. It should also be

151 noted that the overbank and channel facies have undergone minimal subaerial weathering

152 (Weissmann et al., 2002).

153 As a starting point in the interpretation of our data, we assume that the comminution ages

154 of the fine-grained Kings River Fan sediments are equal to the inferred depositional ages based

155 on the literature-derived chronostratigraphic model for eastern San Joaquin Valley deposits

156 (Figure 3b). The assumption of negligible transport and storage time is reasonable, given that

157 large quantities of meltwater during glacial retreats would have provided an efficient means of

158 sediment transport. Indeed, the Kings River Fan paleochannel was considerably wider ( $625 \mathrm{~m}$

159 wide) with a straighter planform than the present-day channel (Weissman et al., 2002),

160 suggesting a past river system with large sediment transport capacity. Aerial views of the Kings

161 River drainage system also reveal almost no areas along the present-day channels where

162 sediment could be stored for significant quantities of time. There is, however, a possibility that a 
163 small fraction of the finer-grained sediment components could be aeolian in origin, in which case

164 a sample's comminution age could be significantly older than its depositional age.

\section{Methods}

In order to obtain the $\left({ }^{234} \mathrm{U} /{ }^{238} \mathrm{U}\right)$ activity ratio of the detrital component as a function of

170 grain size, the following five steps were performed on the raw samples identified in Figure 3b: 1)

171 sequential leaching to remove nondetrital phases, modified from Tessier et al. (1979), 2) wet

172 sieving and filtration using a Fritsch microsieve apparatus fitted with nylon sieve mesh and an

173 Anopore filter, 3) dissolution of up to $100 \mathrm{mg}$ of solid sample with a procedure employing HF,

$174 \mathrm{HNO}_{3}, \mathrm{HClO}_{4}, \mathrm{HCl}$, and $\mathrm{H}_{3} \mathrm{BO}_{3}$ acids, 4) column chemistry to isolate elemental $\mathrm{U}$, modified

175 from Luo et al. (1997), and 5) mass spectrometry to obtain high-precision U isotopic

176 compositions, with measurements made using a Micromass Isoprobe multicollector inductively-

177 coupled plasma mass spectrometer (MC-ICP-MS) (Christensen et al., 2004). Steps 3-5 follow

178 conventional isotope geochemistry methods. Scanning electron microscopy (SEM) images

179 showing a typical sample before and after both leaching and sieving (steps 1 and 2) are shown in

180 Figure 4.

181 In addition to the $\mathrm{U}$ isotope measurements, $\mathrm{Nd}$ and $\mathrm{Sr}$ isotopes of the leached bulk

182 (unsieved) samples were measured in order to determine sediment provenance, since the Sierra

183 Nevada Batholith has a rough east-west gradient in Nd and Sr isotopes (Kistler, 1993). Further

184 sample characterization was performed to obtain grain size distributions, measured using a

185 Coulter particle analyzer, mineralogy by powder x-ray diffraction (XRD), and grain morphology 
186 and surface textures by scanning electron microscopy (SEM). Isotopic and grain size data are

187 given in Table 1, and full methods are described in detail in Appendix A (Supplemental

188 Information).

190 5. Results and discussion

191

\subsection{Uranium isotope patterns}

The uranium isotope results for sieved grain size separates and bulk samples (Figures 5

195 and 6a; Table 1) have many of the features expected if ${ }^{234} \mathrm{U}$ is lost from sediment grains

196 primarily due to alpha recoil. All of the samples have $\left({ }^{234} U /{ }^{238} U\right)<1$ (secular equilibrium),

197 indicating depletion of the ${ }^{234} \mathrm{U}$ daughter isotope. The comminution age model assumes that the

198 grains' initial $\left({ }^{234} \mathrm{U} /{ }^{238} \mathrm{U}\right)=1$ for our nonporous parent material, and the high values of the

199 youngest samples (0.9820 to 0.9978$)$ suggest that this is a good assumption. The recoil model

200 predicts larger ${ }^{234} \mathrm{U}$ depletions with increasing age, and the $\left({ }^{234} \mathrm{U} /{ }^{238} \mathrm{U}\right)$ values generally decrease

201 with greater core depth for a given sieved size fraction (Figure 5). The deviation of the $21.34 \mathrm{~m}-$

202 depth sample from this age trend is discussed in Section 5.3.4.

203 Larger ${ }^{234} \mathrm{U}$ depletions are also expected as grain size decreases. Indeed, with the

204 exception of the youngest sample, grains $<6 \mu \mathrm{m}$ in diameter are more depleted in ${ }^{234} \mathrm{U}$ than the

$205 \quad 10-20 \mu \mathrm{m}$ grains, and the $10-20 \mu \mathrm{m}$ grains are more depleted relative to the $>20 \mu \mathrm{m}$ size

206 fraction. Furthermore, the difference in $\left({ }^{234} \mathrm{U} /{ }^{238} \mathrm{U}\right)$ values between the $<6 \mu \mathrm{m}$ fraction and the

207 larger size fractions increases with age, as anticipated. The strong correlation between the

$208\left({ }^{234} \mathrm{U} /{ }^{238} \mathrm{U}\right)$ trends with depth for the unsieved and $>20 \mu \mathrm{m}$ samples (Figure $\left.6 \mathrm{a}\right)$ and the bulk 
209 grain size distributions (Figure 6b) also reflects the importance of grain size in controlling the

210 magnitude of ${ }^{234} \mathrm{U}$ depletion.

211 The $\left({ }^{234} \mathrm{U} /{ }^{238} \mathrm{U}\right)$ activities are similar to those previously measured for fine-grained deep-

212 sea sediments. The KRF sediments have ${ }^{234} \mathrm{U}$ depletions mostly in the range of $1-8 \%$,

213 comparable to the 3 - 9\% depletions observed for 0 - 400 ka North Atlantic drift sediments with

214 short transport times and average grain sizes of 10-20 $\mu \mathrm{m}$ (DePaolo et al., 2006).

\section{5.2. Glacial origin of sediments}

The glacial origin and unweathered nature of the fine-grained KRF core sediment is

219 supported by $\mathrm{Nd}$ and $\mathrm{Sr}$ isotope measurements for provenance and SEM images of grain

220 surfaces. In the Kings River basin, the ranges of values for the $\mathrm{Nd}$ and $\mathrm{Sr}$ isotopic gradients

221 across the Sierra Batholith, from west to east, are approximately from +6 to $-7 \varepsilon_{\mathrm{Nd}}$ units and from

2220.704 to 0.709 for ${ }^{87} \mathrm{Sr} /{ }^{86} \mathrm{Sr}$ (Kistler, 1993). The isotopic values for the fine-grained channel and

223 overbank deposits (Table 1) indicate that the provenance of most of the sediment is the plutonic

224 rocks located in the eastern part of the range near the Sierran ridge crest, the high-elevation

225 region most affected by Pleistocene glaciations. X-ray diffraction indicates a uniform granitic

226 bulk mineralogy for the fine-grained sediments. SEM images of grain surfaces reveal features

227 indicating glacial abrasion and limited subaerial weathering (angular shapes, fresh breakage

228 surfaces, step fractures, chattermarks, and parallel gouges \& striations) (e.g., Sharp and Gomez, 229 1986). 
After obtaining the measured $\left({ }^{234} \mathrm{U} /{ }^{238} \mathrm{U}\right)$ values for the detrital fraction (Section 5.1), two

237 variables remain unknown in the comminution age expression (Equation 1): the recoil loss factor

$238 f_{\alpha}$ and the comminution age $t_{\text {comm }}$. The critical unknown parameter is $f_{\alpha}-$ if the appropriate $f_{\alpha}$

239 values can be determined, then it is possible to calculate comminution ages from the measured

$240 \quad\left({ }^{234} \mathrm{U} /{ }^{238} \mathrm{U}\right)$ values for samples where there are no independent constraints on the sediment age.

241 Conversely, if the comminution ages are known, information about the behavior of the $f_{\alpha}$ value

242 can be obtained. If both parameters are known, the accuracy of the comminution age method can

243 therefore be evaluated by inputting one of the two variables into Eqn. 1, solving for the

244 remaining parameter, and comparing the calculated value to the known value.

245 There are constraints on the $f_{\alpha}$ and $t_{\text {comm }}$ values for the Kings River Fan core sediments,

246 but the available information for both parameters is limited and carries significant uncertainty.

247 Therefore, although the measured $\left({ }^{234} \mathrm{U} /{ }^{238} \mathrm{U}\right)$ values for the KRF sediments behave in a manner

248 consistent with the recoil-based comminution age model - indicating that the method has the

249 potential to successfully date terrestrial sediments - it is not possible to evaluate the accuracy of

250 the method to high precision with the currently-available information.

251 In spite of the uncertainties in the $f_{\alpha}$ and $t_{c o m m}$ values parameter values, Eqn. 1 can still be

252 used to assess the first-order accuracy of the comminution ages, as well as elucidate trends in the

253 behavior of $f_{\alpha}$ for the KRF sediments. In Sections 5.3.3 and 5.3.4, we present two sets of

254 calculated comminution ages that utilize different approaches to estimating $f_{\alpha}$. We show that 
255 even simple models for estimating $f_{\alpha}$ yield comminution ages that are plausible. The

256 discrepancies between the literature-derived depositional ages and the calculated comminution

257 ages suggest that 1) $f_{\alpha}$ is dependent on grain size, and 2) either $f_{\alpha}$ is age-dependent, or the KRF

258 core sediments were deposited with a more constant deposition rate than indicated by the

259 literature-derived age-depth model.

260

261 5.3.2. Describing $f_{\alpha}$ in terms of surface roughness

262

It is useful to discuss the recoil loss parameter $f_{\alpha}$ in terms of the surface roughness factor

$264 \lambda_{r}$; this change of variables facilitates comparison with existing data describing sediment grain

265 surfaces. The surface roughness factor (Helgeson et al., 1984; Jaycock and Parfitt, 1981; Anbeek

266 et al., 1994) relates the smooth-surface geometric surface area to the actual surface area, which

267 has 'roughness' (encompassing both small-lengthscale surface topography as well as internal

268 grain surface area). As shown by DePaolo et al. (2006), $f_{\alpha}$ is generally much greater (10 - 50

269 times) than would be expected if the sediment grains were smooth spheres. The additional loss

270 of ${ }^{234} \mathrm{U}$ implied by these elevated $f_{\alpha}$ values can be accounted for by the presence of grain surface

271 roughness, which greatly increases the surface area over which recoil loss occurs. We can thus

272 represent the recoil loss factor in terms of $\lambda_{r}$ and the geometric grain size, which is well-

273 constrained for our sieved size fractions, through the following equations:

274

275

$f_{\alpha}=\frac{1}{4} L \cdot S_{t o t} \cdot \rho$

276 
277 (Semkow, 1990; DePaolo et al., 2006), where $L$ is the recoil distance (34 nm; Sun and Semkow,

278 1998), $\rho$ is the bulk density (assumed to be $2.65 \times 10^{6} \mathrm{~g} / \mathrm{m}^{3}$ ), and $S_{t o t}$ is given by the formulation

279 of Anbeek et al. (1994) as:

280

$281 S_{\text {tot }}=S_{\text {geom }} \cdot \lambda_{r}=(K / \rho d) \cdot \lambda_{r}$

282

283 where $S_{\text {geom }}\left(\mathrm{m}^{2} / \mathrm{g}\right)$ is the geometric specific surface area, $K$ is a dimensionless grain shape factor 284 (Cartwright, 1962) equal to 6 for a sphere, and $d$ is the grain diameter. $f_{\alpha}$ can then be related to 285 the surface roughness by:

$287 f_{\alpha}=\frac{L K}{4 d} \lambda_{r}$

Many studies where sediment surface areas are measured via gas adsorption techniques

290 show that roughness is indeed significant, and grain surface areas have been estimated to be

291 anywhere from several to hundreds of times larger than those calculated with a smooth sphere

292 model (e.g., White and Peterson, 1990; Anbeek et al., 1994; Brantley and Mellott, 2000). For

293 example, silicate samples freshly crushed or ground by mortar \& pestle in the laboratory show

294 relatively constant $\lambda_{r}=7$ across a wide range of grain sizes (White and Peterson, 1990; Brantley

295 and Mellott, 2000). However, studies of naturally-weathered samples suggest that $\lambda_{r}$ increases

296 with both increasing grain size (White and Peterson, 1990; Anbeek et al., 1994) and duration of

297 subaerial weathering (White et al., 1996).

298 
A very simple approach for determining comminution ages from $A_{\text {meas }}$ yields ages that are

302 plausible, even on unsieved bulk samples. In this starting case, we calculate $f_{\alpha}$ for each sample

303 from Eqn. 4, assuming all samples have common values of $\lambda_{r}=7$, as suggested by previous

304 studies, and $K=6$. To determine $d$ values, we use the grain size distributions (GSDs) measured

305 by the Coulter analyzer to determine the grain diameter corresponding to the weighted average of

306 the smooth-sphere specific surface area over the size range of interest. (For bulk samples, the

307 size range is the full GSD; for the $<6 \mu \mathrm{m}$ size fraction, the GSD is extrapolated down to 0.02

$308 \mu \mathrm{m}$, the pore size of the wet-sieving filter). Comminution ages calculated with Eqn. 1 using

$309 A_{\text {meas }}$ and these $f_{\alpha}$ values are shown in Figure 7a. The ages for the bulk samples are within the

310 range expected for these samples, and are similar to, although somewhat younger than, the

311 literature values. This suggests that a straightforward first-order approach can provide useful

312 information; e.g. the data indicate that the sediments are Late Quaternary in age and accumulated 313 over a time period of ca. $500 \mathrm{kyr}$.

314 Surface roughness factors that vary as a function of grain size are, however, likely to be 315 more appropriate than a constant value of $\lambda_{r}=7$. In Figure $7 \mathrm{a}$, the $10-15 \mu \mathrm{m}$ and $15-20 \mu \mathrm{m}$ size

316 fractions require larger $\lambda_{r}$ in order to agree with the literature ages, whereas the $<6 \mu \mathrm{m}$ fraction

317 requires smaller $\lambda_{r}$. Increasing $\lambda_{r}$ with increasing grain size would also be consistent with

318 previous studies of granitic sediment surface area (White and Peterson, 1990; Anbeek et al.,

319 1994). Figure $7 \mathrm{~b}$ shows the $\lambda_{r}$ values required to match the measured $\left({ }^{234} \mathrm{U} /{ }^{238} \mathrm{U}\right)$ ratios to the

320 literature-derived ages through Eqns. 1 and 4, and there are clear trends as a function of grain

321 size. These trends indicate that, for natural samples, $f_{\alpha}$ is a more complicated function of grain 
322 size (and surface area) than previously suggested from considerations of grain geometry alone

323 (e.g., Kigoshi, 1971). Although this analysis relies on the literature sediment ages, we find that

324 using a simple linear age-depth curve instead of the literature ages (solid gray line in Figure 7a)

325 produces relationships between $\lambda_{r}$ and grain size that differ only slightly from those shown in

326 Figure $7 \mathrm{~b}$. This reflects the high sensitivity of $t_{\text {comm }}$ to $f_{\alpha}$ (and hence $\lambda_{r}$ ) values.

328 5.3.4. Calculating $t_{\text {comm }}$ using $f_{\alpha}$ from the oldest samples

As an alternative to imposing independent estimates of $\lambda_{r}$, the measured $\left({ }^{234} \mathrm{U} /{ }^{238} \mathrm{U}\right)$

331 values for the oldest samples can be used to assess $f_{\alpha}$ because as the comminution age

332 approaches $1 \mathrm{Ma},\left({ }^{234} \mathrm{U} /{ }^{238} \mathrm{U}\right)$ values should approach a steady-state value of $1-f_{\alpha}(\mathrm{cf}$. DePaolo et

333 al., 2006). In addition to being the oldest sample, the sample at $43.80 \mathrm{~m}$ depth has the best

334 independently-constrained age, since it is near the depth of the 780 ka Matuyama-Brunhes

335 magnetic reversal at $\sim 41 \mathrm{~m}$. We use Eqn. 1 to calculate a set of $f_{\alpha}$ values corresponding to the

336 bulk sample and size fractions of the $43.80 \mathrm{~m}$ sample, employing the literature-derived age of

$337820 \mathrm{ka}$ and the measured $\left({ }^{234} \mathrm{U} /{ }^{238} \mathrm{U}\right)$. This set of $f_{\alpha}$ values is then applied to the younger samples

338 to determine $t_{\text {comm }}$, thus taking into account the variation in $f_{\alpha}$ with grain size (discussed in terms

339 of $\lambda_{r}$ above). The comminution age-depth curve produced by this approach (Figure 8) resembles

340 the curve for bulk samples with $\lambda_{r}=7$ (Figure 7a), with ages that are plausible but younger than

341 the literature age-depth curve.

342 There are two possible explanations for the younger-than-expected ages that we obtain

343 using the comminution method. Although markedly less robust than the $\lambda_{r}$ trend as a function of

344 grain size, the first possibility is an unaccounted-for increase in $\lambda_{r}$ (and hence $f_{\alpha}$ ) as a function of 
345 age within the Turlock Lake Formation (colored data points in Figure 7b). This age dependence 346 could be a weathering-induced effect, such as the increase in $\lambda_{r}$ with age observed by White et al.

347 (1996). An explanation for why the $21.34 \mathrm{~m}$ sample has larger-than-expected $\lambda_{r}$ is suggested by

348 the grain size distributions of the bulk samples - the distribution for the $21.34 \mathrm{~m}$ sample is

349 markedly skewed towards finer grain sizes relative to the other samples (Figure 6b), although the

350 bulk mineralogy as determined by XRD is essentially identical. This suggests that this sample

351 was subjected to either different formation or sorting processes than the other samples, which 352 may either generate or select for grains with different characteristic $\lambda_{r}$ values. For example, if

353 this sample was subjected to more vigorous glacial grinding that produced a larger population of 354 small grains, this could have generated more roughness and porosity in the form of microcracks

355 (Hodson, 1998). It is also possible that the $21.34 \mathrm{~m}$ sample is partly composed of older reworked 356 sediment, which would lead to an apparent larger $\lambda_{r}$ needed to relate $A_{\text {meas }}$ to the literature age 357 model.

358 A second possible explanation for the offset between the calculated comminution ages 359 and the literature ages is that the middle part of the core could be younger than previously 360 inferred. Although the correlations and age inferences discussed in Marchand and Allwardt 361 (1981) and Lettis (1988) are quite reasonable, there are in fact no preexisting direct age 362 determinations on the actual KRF sediments and only minimal paleomagnetic age constraints on 363 KRF core B5. If the calculated comminution ages for the KRF core sediments (Figure 8) are the 364 correct ages, then the age-depth model is roughly linear. A constant deposition rate is not wholly 365 consistent with the accepted model for episodic fan deposition, but an age-depth model that is 366 more linear than the current literature-derived model is not entirely implausible. This is because, 367 as discussed in Section 3, there is uncertainty in the age of the Friant Pumice that constrains the 
368 age of the top of the Upper Turlock Lake Unit. In addition to these two possible explanations for

369 the discrepancy between calculated comminution ages and literature ages, there may be potential

370 complications with the comminution age method that we do not yet fully understand.

371 To summarize the findings discussed in Section 5.3 that are relevant to future

372 applications of the comminution age method, deviations from expected comminution ages

373 illuminate $f_{\alpha}$ trends with grain size and possibly age, which must be taken into account if the

374 above approaches to calculating $t_{\text {comm }}$ are used. To further improve the accuracy of the

375 comminution age dating method, and to apply it to sediments that do not have independent age

376 constraints, both 1) weathering effects and 2) perhaps more sophisticated approaches to

377 determining $f_{\alpha}$ must be considered. These are discussed in Sections 5.4 and 5.5, respectively.

\subsection{Effects of leaching and weathering}

An argument for alpha recoil as the dominant process generating ${ }^{234} \mathrm{U}_{-}{ }^{238} \mathrm{U}$ radioactive

383 disequilibrium in the fine-grained Kings River Fan sediments is the similarity of literature $\lambda_{r}$

384 values to those in Figure $7 \mathrm{~b}$, which were calculated assuming that recoil loss alone could account

385 for the full magnitude of the measured $\left({ }^{234} \mathrm{U} /{ }^{238} \mathrm{U}\right)$ deficits. As a point of reference, $\lambda_{r}$ values can

386 exceed 600 (White et al. 1996). By comparison, the inferred surface roughness values of the

387 KRF samples (approximately 1 to 17 ), are quite similar to values given for: 1) granitic glacial

388 outwash $\left(\lambda_{r}=\sim 0\right.$ to 8 for individual minerals $<20 \mu$ m diameter; Anbeek et al., 1994), 2) the

389 youngest soil of the Merced chronosequence, which is composed of the same glacial outwash

390 units from the Sierra Nevada as the nearby KRF sediments $\left(\lambda_{r}=21\right.$; White et al., 1996), and 3) 
391 fresh laboratory-ground silicates ( $\lambda_{r}=7$; White and Peterson, 1990; Brantley and Mellott, 2000).

392 However, it is also possible that preferential leaching of ${ }^{234} \mathrm{U}$, either naturally or during the

393 sample pretreatment, has enhanced the apparent ${ }^{234} \mathrm{U}$ loss (Kolodny and Kaplan, 1970; Osmond

394 and Ivanovich, 1992), since the $\lambda_{r}$ values we calculate are somewhat larger than expected. This

395 is based on comparison with the results of White et al. (1996) and Anbeek (1994), from which

396 one would infer smaller values of $\lambda_{r}$ in $\leq 20 \mu \mathrm{m}$ samples. A strong argument against significant

$397{ }^{234} \mathrm{U}$ loss from preferential leaching, however, is that the youngest KRF samples $(\sim 200 \mathrm{ka})$ have

398 very small depletions of ${ }^{234} \mathrm{U}$ of order $1 \%$. Note also that previous studies of naturally-

399 weathered samples have not explicitly dealt with small grains in the size ranges of our sieved

400 samples, and extrapolating the $\lambda_{r}$ trends from coarser samples may not be fully accurate.

401 One caveat in directly comparing literature $\lambda_{r}$ values to those in Figure $7 \mathrm{~b}$ is that the

402 lengthscale of the measurement probe differs in these two cases. Surface areas are most

403 commonly measured by BET gas adsorption. Since the characteristic lengthscale of alpha recoil

$404(L=34 \mathrm{~nm})$ is two orders of magnitude greater than the length of the BET adsorbate molecules

405 (typically $\mathrm{N}_{2}$, with a diameter of $\sim 0.35 \mathrm{~nm}$ ), the $S_{\text {tot }}$ surface areas obtained by the two methods

406 can only be directly compared if the roughness of the surface is greater than or equal to the recoil

407 lengthscale. This may be likely, since most natural minerals at the Earth's surface are

408 dominantly mesoporous (Rama and Moore, 1984; Brantley and Mellott 2000, and refs. therein),

409 where mesoporous is defined as having a characteristic porosity (roughness) lengthscale of 2-50

$410 \mathrm{~nm}$. If there is substantial microporosity $(<2 \mathrm{~nm})$, BET-determined values of $\lambda_{r}$ from the

411 literature will yield values that are larger than recoil-based $\lambda_{r}$.

412 When surface roughness is parameterized in terms of fractal dimension $(D)$, a similarity

413 between literature $D$ values and those for the KRF sediments also is revealed. For surfaces, 
414 values for $D$ typically range from $2 \leq D<3$, where 2 corresponds to Euclidean geometry (i.e., no

415 surface roughness) and 3 corresponds to an infinitely rough surface. The recoil loss factor $f_{\alpha}$ is

416 related to $D$ by the following scaling relationship from Semkow (1991):

$418 f_{\alpha} \propto d^{(D-3)}$

420 Therefore, on a plot of $\log f_{\alpha}$ vs. $\log d$, the slope of a line will be equal to $(D-3)$. We obtain the

421 fractal dimension by first using $A_{\text {meas }}$ and literature ages to calculate $f_{\alpha}$ values for the KRF sieved

422 size fractions, then plotting against the grain diameter $d$ values. A linear least-squares regression

423 yields the following fractal dimensions for the Turlock Lake Formation samples: for samples at

424 depths of $12.59,21.34,31.24$, and $43.80 \mathrm{~m}$, the corresponding fractal dimensions are $2.58 \pm 0.12$,

$4252.82 \pm 0.01,2.65 \pm 0.05$, and $2.50 \pm 0.12$, respectively, where uncertainties are standard errors on

426 the regression slope. We are unable to determine a meaningful $D$ for the $3.81 \mathrm{~m}$ Riverbank

427 Formation sample because the $<6 \mu \mathrm{m}$ fraction is not the most depleted size fraction. These

428 relatively high $D$ values for the other KRF samples are similar to the range of $D$ values obtained

429 by both molecular tiling and radon emanation methods for other rocks and soils (Avnir et al.,

430 1984; Avnir et al., 1985; Semkow, 1991), lending further support to the idea that alpha recoil can

431 fully account for the magnitude of $\left({ }^{234} U /{ }^{238} U\right)$ depletion. It should be noted that an advantage of

432 using this Rn emanation method of Semkow (1991) to get $D$ is that the resulting fractal

433 dimensions are relevant for describing self-similarity on the lengthscale of recoil (tens of $\mathrm{nm}$ ).

434 In addition to preferential leaching of ${ }^{234} \mathrm{U}$, other complicating factors from weathering

435 can affect the $\mathrm{U}$ isotopic composition of sediment grains. The simplest model of weathering is

436 the progressive dissolution and removal of the grains' surface layer, which reduces the diameter 
437 and partially removes the outer rinds depleted in ${ }^{234} U$ by the recoil process. In this model, if 438 weathering occurs at a fast enough rate (DePaolo et al., 2006), the magnitude of the ${ }^{234} U$

439 depletion would be limited, thereby skewing the comminution ages to lower values. Weathering 440 rates have been studied extensively for developed soils, but data are scarce for sediments that are 441 barely subjected to soil-forming processes, as is the case for most of the KRF samples we 442 analyzed. One study that does investigate such sediments is Maher et al. (2003). In this study, 443 the deduced bulk weathering rate for the 15 - 700 ka granitic sediments of the Hanford 444 Formation in south-central Washington State is $3 \times 10^{-17} \mathrm{~mol} / \mathrm{m}^{2} / \mathrm{sec}$ when referenced to the 445 smooth-sphere model surface area of the sediments. However, considering that the grains' 446 surface area is roughly ten times the smooth-sphere area, this rate corresponds to a timescale of 447 roughly 3500 kya to dissolve a surface layer of thickness equal to the recoil distance of $34 \mathrm{~nm}$.

448 The dissolution timescale is therefore about ten times the timescale for ${ }^{234} \mathrm{U}$ depletion by recoil, 449 so weathering may not significantly retard the growth of ${ }^{234} \mathrm{U}$ depletion effects.

450 It is also possible that weathering can promote ${ }^{234} \mathrm{U}$ depletion if the dominant weathering 451 effect is an increase in surface roughness rather than dissolution and removal of ${ }^{234} \mathrm{U}$-depleted 452 grain surface regions. Enhanced ${ }^{234} \mathrm{U}$ recoil loss with sample aging could explain the young 453 comminution ages obtained when $f_{\alpha}$ is estimated from the oldest sample (Section 5.3.4). Excess 454 recoil loss would be facilitated if the dissolution process that generates increased roughness only 455 partially samples the ${ }^{234} \mathrm{U}$-depleted regions. This would be the case if mineral dissolution occurs 456 mainly from pore bottoms, which comprise a small proportion of the total surface area (Anbeek 457 et al., 1994).

458 The coarse-grained, moderately mature paleosol sample at $8.38 \mathrm{~m}$ depth (Table 1) 459 provides some indication about the possible effects of long-term and/or intense subaerial 
460 weathering. This sample shows anomalous behavior when compared to the glacial flour samples 461 - values of $\left({ }^{234} \mathrm{U} /{ }^{238} \mathrm{U}\right)$ decrease with increasing grain size, and all $\left({ }^{234} \mathrm{U} /{ }^{238} \mathrm{U}\right)$ values are greater 462 than the secular equilibrium value. The grain size trend may be explained by factors that are 463 correlated with available surface area, given the decreasing surface area to volume ratio as grain 464 size increases. Possible factors include the presence of secondary grain coatings with high U 465 concentrations and/or high $\left({ }^{234} \mathrm{U} /{ }^{238} \mathrm{U}\right)$ (e.g., Plater et al., 1992) which may provide a source for 466 implanted ${ }^{234} \mathrm{U}$, or be incompletely removed during the sequential leaching sample pretreatment.

467 In addition to the high- $-{ }^{234} \mathrm{U}$ nondetrital phases directly targeted by the sequential leaching 468 pretreatment (Table A1), secondary phases formed by weathering can preferentially concentrate $469{ }^{234} \mathrm{U}$ (e.g., Pelt et al., 2008), particularly illite and montmorillonite (Shirvington, 1983).

\subsection{Additional means of independently determining $f_{\alpha}$}

In addition to the approaches discussed in Section 5.3, several other methods may be used 475 to independently determine the value of the $f_{\alpha}$ parameter needed to calculate $t_{\text {comm }}$ from the 476 measured $\left({ }^{234} \mathrm{U} /{ }^{238} \mathrm{U}\right)$ values using Eqn. 1 (Table 2). An advantage of the methods discussed in 477 this section is that $f_{\alpha}$ may be directly determined for each individual sample. This may lead to 478 more precise and accurate comminution ages for a given sample.

479 One approach is to measure $\left({ }^{226} \mathrm{Ra} /{ }^{230} \mathrm{Th}\right)$ activity ratios on the same samples for which 480 the $\left({ }^{234} \mathrm{U} /{ }^{238} \mathrm{U}\right)$ values are determined (DePaolo et al., 2006). Compared to the ${ }^{238} \mathrm{U}_{-}{ }^{234} \mathrm{U}$ parent481 daughter pair, the alpha recoil decay of ${ }^{230} \mathrm{Th}$ to ${ }^{226} \mathrm{Ra}$ - also in the ${ }^{238} \mathrm{U}$ decay chain - has a 482 similar recoil distance but a much shorter half life of only 1599 yrs. Therefore, the $\left({ }^{230} \mathrm{Th} /{ }^{226} \mathrm{Ra}\right)$ 
483 value will reach the $1-f_{\alpha}$ steady state value relatively quickly (within $\sim 10 \mathrm{ka}$ ). For samples older 484 than $\sim 10 \mathrm{ka}$, the $f_{\alpha}$ value determined from the steady-state value of ${ }^{230} \mathrm{Th}_{-}{ }^{226} \mathrm{Ra}$ can then be 485 applied to the ${ }^{238} \mathrm{U}_{-}^{234} \mathrm{U}$ system, with a minor correction for the slight difference in recoil 486 distance for the different parent-daughter pairs $\left(\sim 37 \mathrm{~nm}\right.$ recoil distance for the ${ }^{230} \mathrm{Th}$ decay (Sun 487 and Semkow, 1998)). A small correction may also be needed to account for the recoil loss of 488 some of the ${ }^{234} \mathrm{U}$ precursor to ${ }^{230} \mathrm{Th}$.

489 Gas adsorption measurements can be used in several ways to determine $f_{\alpha}$. The first way 490 is to measure the grain surface area over which alpha recoil occurs, allowing $f_{\alpha}$ to be calculated 491 using Eqn. 2. As discussed in Section 5.4, the 'yardstick' for obtaining surface areas via the 492 commonly-used BET model for gas adsorption is the lengthscale associated with the adsorbate 493 molecule. Therefore, BET surface areas can provide a direct measurement of the surface area 494 over which recoil occurs only if the lengthscale of the sample surface roughness is roughly equal 495 to or greater than the recoil lengthscale (i.e., mesoporous and macroporous solids, with minimal 496 microporosity that can contribute additional superfluous surface area). If BET surface areas are 497 used to calculate $f_{\alpha}$, the accompanying full adsorption/desorption isotherm should also be 498 measured to characterize the pore size distribution of the sample.

499 Another way of using gas adsorption measurements to determine $f_{\alpha}$ is to employ a grain 500 surface area model that relates the angstrom-scale surface structures probed by BET analysis to 501 the larger recoil-lengthscale roughness. One such model is that of Semkow (1990), which 502 describes the surface from which recoiled daughters are ejected as having fractal geometry. To 503 obtain $f_{\alpha}$, the following relation may be used (Semkow, 1990; Bourdon et al., 2009): 
$505 \quad f_{\alpha}=\frac{1}{4}\left\lfloor\frac{2^{D-1}}{4-D}\left(\frac{a}{L}\right)^{D-2}\right\rfloor L \cdot S_{B E T} \cdot \rho$

507 where $S_{B E T}$ is the measured BET surface area and $a$ is the adsorbate molecule diameter $(0.35 \mathrm{~nm}$

508 for $\mathrm{N}_{2}$ ). The fractal dimension $D$ must be determined independently, which can also be done

509 with gas adsorption measurements.

510 There are three approaches for obtaining fractal dimensions at recoil lengthscales

511 (Jaroniec, 1995; Lowell et al., 2004), which are comparable to mesoporosity lengthscales. The

512 first is through the use of the Frenkel-Halsey-Hill (FHH) adsorption isotherm equation (Avnir

513 and Jaroniec, 1989; Yin, 1991). The FHH relation states that $N \propto\left[\ln \left(P_{0} / P\right)\right]^{D-3}$, where $N$ is the

514 amount of adsorbed gas at the relative pressure $P / P_{0}, P$ is the equilibrium gas pressure, and $P_{0}$ is

515 the saturation pressure. Therefore, on a plot of $\ln N$ vs. $\ln \left(\ln \left(P / P_{0}\right)\right.$, the fractal dimension can be

516 obtained from the slope of $(D-3)$. This relation holds for relative pressures in the capillary

517 (pore) condensation regime. The second approach is the Neimark-Kiselev (NK) thermodynamic

518 method (Neimark, 1990; Neimark 1992), in which the characteristic lengthscale of the

519 measurement 'yardstick' is $a_{c}$, the mean radius of meniscus curvature for the condensed

520 adsorbate within a pore. In the NK model, $S_{\mathrm{lg}}=K a_{c}{ }^{2-D}$. Here $K$ is a constant, the adsorbate-

521 vapor (liquid-gas) interfacial area $S_{l g}$ can be calculated using the Kiselev equation, and $a_{c}$ is

522 related to the relative pressure through the Kelvin equation (Neimark, 1990). The third method

523 for obtaining $D$ is through the slope of a $\log$ - $\log$ plot of the pore size distribution $J(r)$, where $r$ is

524 the average pore radius (Jaroniec, 1995): $J(r) \propto r^{2-D}$. Previous studies indicate that the FHH and 525 NK methods can be equivalent (Jaroniec, 1995; Sahouli et al., 1996). 


\section{Conclusions}

To investigate whether continental sediments can be dated to useful accuracy with the

531 uranium-series comminution age method, we applied the method to the glacigenic alluvial

532 deposits of the Kings River Fan. Samples were obtained from a 45 meter-long drill core that

533 contains minimally-weathered sediment deposited since $\sim 800$ kya. Independent age estimates on

534 the sediments are available, although they are based on stratigraphic correlations to other alluvial

535 fan sections north of our sampling site. The glacial origin of the sediments was verified using

$536 \mathrm{Nd}$ and $\mathrm{Sr}$ isotopes, as well as SEM imaging. Precise U isotopic measurements were made on

537 bulk sediment and sieved grain size fractions, all of which were first sequentially leached to 538 remove nondetrital phases.

539 Based on our results, the U-series comminution age method appears to have promise for

540 dating continental sediments, although there is need for considerable further work. The U

541 isotope ratios for the KRF samples behave in a manner consistent with the comminution age

542 model, where ${ }^{234} \mathrm{U}$ loss primarily occurs due to alpha recoil. The $\left({ }^{234} \mathrm{U} /{ }^{238} \mathrm{U}\right)$ activity ratios of

543 bulk sediment samples, as well as the $>20 \mu \mathrm{m}, 15-20 \mu \mathrm{m}, 10-15 \mu \mathrm{m}$, and $<6 \mu \mathrm{m}$ fractions, have

$544{ }^{234} \mathrm{U}$ depletions of up to $9 \%$ (relative to secular equilibrium) that generally increase down core.

545 The $\left({ }^{234} \mathrm{U} /{ }^{238} \mathrm{U}\right)$ values also depend on grain size: the smallest grains $<6 \mu \mathrm{m}$ in diameter are

546 more depleted in ${ }^{234} \mathrm{U}$ than the larger 10-20 $\mu \mathrm{m}$ grains, and the 10-20 $\mu \mathrm{m}$ grains are more

547 depleted relative to the $>20 \mu \mathrm{m}$ size fraction.

$548 \quad$ The deduced ages for the KRF samples are plausible even for relatively crude approaches

549 to the data interpretation. Calculated comminution ages are obtained by using two simple 
approaches to determining the recoil loss parameter $\left.f_{\alpha}: 1\right)$ using a constant value of $\lambda_{r}$, and 2)

551 applying $f_{\alpha}$ values derived from the $\left({ }^{234} \mathrm{U} /{ }^{238} \mathrm{U}\right)$ values from the oldest KRF samples. The age

552 estimates we derive for KRF sediments using these approaches are 50 to 100 kya at the top of the

55345 meter section and 500 to 800 kya at the bottom. For comparison, the available age and

554 correlation analysis from the literature suggests that the sediment ages are between 200 and 800

555 ka. Deviations from the literature-derived age-depth model for the grain size separates suggest

556 that $\lambda_{r}$ increases with increasing grain size and possibly age. The ranges of values for $\lambda_{r}$ ( 1 to

557 17) and the fractal dimension $D$ (2.50 to 2.82) are consistent with alpha recoil loss of ${ }^{234} \mathrm{U}$ being

558 the main cause of ${ }^{234} \mathrm{U}$ depletions in the sediments.

559 Further work is needed in order to determine the role of weathering (including the

560 processes of mineral dissolution and aqueous leaching of $\left.{ }^{234} U\right)$ in affecting the $\left({ }^{234} U /{ }^{238} U\right)$ values

561 of the detrital sediment fraction. ${ }^{238} \mathrm{U}^{234} \mathrm{U}_{-}{ }^{230} \mathrm{Th}$ disequilibrium may be useful for investigating

562 these weathering processes. The anomalous behavior of a moderately mature paleosol sample

563 indicates that intensely weathered samples may have $\left({ }^{234} \mathrm{U} /{ }^{238} \mathrm{U}\right)$ values that reflect the $\mathrm{U}$

564 concentration and isotopic composition of nondetrital grain coatings.

565 A priority for future work is to obtain more precise values for $f_{\alpha}$ on individual samples.

566 Among the ways this can be done is through the measurement of $\left({ }^{226} \mathrm{Ra} /{ }^{230} \mathrm{Th}\right)$ activities, as well

567 as gas adsorption measurements to characterize the sample surface area. A fractal model for

568 surface roughness can be used to translate BET surface areas into the relevant surface area for

569 recoil loss of ${ }^{234} \mathrm{U}$; creating other models for surface roughness may also be useful. 


\section{Acknowledgements}

575

576 We thank Shaun Brown, Evan Kha, Tom Owens, and Tim Teague for laboratory and technical

577 assistance. Graham Fogg (UC Davis) granted access to samples from KRF core B5, and Bill

578 Dietrich provided comments and allowed us the use of the Coulter particle sizer. We are also

579 grateful for comments from two anonymous reviewers. Funding for this project was provided by

580 National Science Foundation (NSF) grant EAR-0617744, Lawrence Livermore National

581 Laboratory UEPP, and an NSF Graduate Research Fellowship to V.Lee. The work was also

582 facilitated by support from the Department of Energy Office of Basic Energy Sciences under

583 contract DE-AC02-05CH11231 to Lawrence Berkeley National Laboratory. 


\section{References}

Aitken, M.J., 1998. An Introduction to Optical Dating: The Dating of Quaternary Sediments by the Use of Photon-stimulated Luminescence, Oxford University Press, Oxford, UK, 267 pp.

Anbeek, C., Vanbreemen, N., Meijer, E.L., Vanderplas, L., 1994. The Dissolution of Naturally Weathered Feldspar and Quartz. Geochim. Cosmochim. Acta 58 (21), 4601-4613.

Avnir, D., Farin, D., Pfeifer, P., 1984. Molecular Fractal Surfaces. Nature 308 (5956), 261-263.

Avnir, D., Farin, D., Pfeifer, P., 1985. Surface Geometric Irregularity of Particulate Materials the Fractal Approach. J. Colloid Interface Sci. 103 (1), 112-123.

Avnir, D., Jaroniec, M., 1989. An Isotherm Equation for Adsorption on Fractal Surfaces of Heterogeneous Porous Materials. Langmuir 5 (6), 1431-1433.

Brantley, S.L., Mellott, N.P., 2000. Surface area and porosity of primary silicate minerals. Am. Mineral. 85 (11-12), 1767-1783.

Burow, K., Panshin, S.Y., Dubrovsky, N.M., Van Brocklin, D., Fogg, G.E., Evaluation of processes affecting 1,2-Dibromo-3-Chloropropane (DBCP) concentrations in ground water in the eastern San Joaquin Valley, California: Analysis of chemical data and ground-water flow and transport simulations, Water-Resources Investigations, U.S. Geological Survey, 1999, p. 57.

Cartwright, J., 1962. Particle Shape Factors. Ann. Occup. Hyg. 5 163-171.

Chabaux, F., Riotte, J., Dequincey, O., 2003. U-Th-Ra fractionation during weathering and river transport. Uranium-Series Geochemistry 52, 533-576.

Christensen, J.N., Dresel, P.E., Conrad, M.E., Maher, K., Depaolo, D.J., 2004. Identifying the 
sources of subsurface contamination at the Hanford Site in Washington using highprecision uranium isotopic measurements. Environ. Sci. Technol. 38 (12), 3330-3337.

607 DePaolo, D.J., Maher, K., Christensen, J.N., McManus, J., 2006. Sediment transport time measured with U-series isotopes: Results from ODP North Atlantic drift site 984. Earth

Dunne, T., Mertes, L.A.K., Meade, R.H., Richey, J.E., Forsberg, B.R., 1998. Exchanges of

Dietrich, W.E., Bellugi, D., Heimsath, A.M., Roering, J.J., Sklar, L., Stock, J.D., 2003.

Dietrich, W.E., Dunne, T., Humphrey, N.F., Reid, L.M., 1982. Construction of sediment budgets Planet. Sci. Lett. 248 (1-2), 394-410. for drainage basins, in: Swanson, F.J., Janda, R.J., Dunne, T., Swanston, D.N., (Eds), U.S.D.A. Forest Service General Technical Report PNW-141, Pacific Northwest Forest and Range Experiment Station, Portland, Oregon, pp. 5-23.

Geomorphic transport laws for predicting the form and evolution of landscapes. In:

Wilcock, P., Iverson, R., (Eds), Prediction in Geomorphology, AGU Geophysical

Monograph Series 135, pp. 103-132.

Dosseto, A., Bourdon, B., Turner, S.P., 2008. Uranium-series isotopes in river materials: Insights into the timescales of erosion and sediment transport. Earth Planet. Sci. Lett. 265 (1-2), 117. sediment between the flood plain and channel of the Amazon River in Brazil. Geol. Soc. Am. Bull. 110 (4), 450-467.

Gosse, J.C., Phillips, F.M., 2001. Terrestrial in situ cosmogenic nuclides: theory and application. Quat. Sci. Rev. 20 (14), 1475-1560.

Granet, M., Chabaux, F., Stille, P., France-Lanord, C., Pelt, E., 2007. Time-scales of sedimentary transfer and weathering processes from U-series nuclides: Clues from the Himalayan 
rivers. Earth Planet. Sci. Lett. 261 (3-4), 389-406.

629 Hashimoto, T., Aoyagi, Y., Kudo, H., Sotobayashi, T., 1985. Range Calculation of Alpha-Recoil Atoms in Some Minerals Using Lss-Theory. J. Radioanal. Nucl. Chem. 90 (2), 415-438.

Hay, W.W., 1998. Detrital sediment fluxes from continents to oceans. Chem. Geol. 145 (3-4), 287-323.

Helgeson, H.C., Murphy, W.M., Aagaard, P., 1984. Thermodynamic and kinetic constraints on reaction rates among minerals and aqueous solutions. II. Rate constants, effective surface area, and the hydrolysis of feldspar. Geochim. Cosmochim. Acta 48 (12), 2405-2432.

Hodson, M.E., 1998. Micropore surface area variation with grain size in unweathered alkali feldspars: implications for surface roughness and dissolution studies. Geochim. Cosmochim. Acta 62 (21-22), 3429-3435.

Huntington, G.L., 1980. Soil-Land Form Relationships of Portions of the San Joaquin River and Kings River Alluvial Depositional Systems in the Great Valley of California, Ph.D., University of California at Davis.

Janda, R.J., 1966. Pleistocene history and hydrology of the upper San Joaquin River, California,

Jaycock, M.J., Parfitt, G.D., 1981. Chemistry of Interfaces, Ellis Horwood.

647 Kigoshi, K., 1971. Alpha-Recoil Thorium-234: Dissolution into Water and Uranium234/Uranium-238 Disequilibrium in Nature. Science 173 (3991), 47-48.

Kistler, R.W., 1993. Mesozoic Intrabatholithic Faulting, Sierra Nevada, California. In: Dunn, 

Angeles, pp. 274-262.

653 Kolodny, Y., Kaplan, I.R., 1970. Uranium Isotopes in Sea-Floor Phosphorites. Geochim.

$654 \quad$ Cosmochim. Acta 34 (1), 3-24.

655 Last, W.M., Smol, J.P., 2001. Tracking Environmental Change Using Lake Sediments, Klewer 656 Academic Publishers, Dordrecht.

657 Lettis, W.R., 1988. Quaternary Geology of the Northern San Joaquin Valley. In: Graham, S.A., 658 (Ed), Studies of the Geology of the San Joaquin Basin 60, Pacific Section S.E.P.M., pp. 333-351.

Lowell, S., Shields, J.E., Thomas, M.A., Thommes, M., 2004. Characterization of Porous Solids and Powders: Surface Area, Pore Size and Density, Kluwer Academic Publishers, Dordrecht, The Netherlands, 347 pp.

Luo, X.Z., Rehkamper, M., Lee, D.C., Halliday, A.N., 1997. High precision Th-230/Th-232 and U-234/U-238 measurements using energy-filtered ICP magnetic sector multiple collector mass spectrometry. Int. J. Mass Spectrom. 171 (1-3), 105-117.

666 Maher, K., DePaolo, D.J., Conrad, M.E., Serne, R.J., 2003. Vadose zone infiltration rate at Hanford, Washington, inferred from Sr isotope measurements. Water Resour. Res. 39 (8), 1204.

Maher, K., DePaolo, D.J., Christensen, J.N, 2006, U-Sr Isotopic Speedometer: Fluid flow and Chemical Weathering Rates in Aquifers. Geochimica et Cosmochimica Acta, v. 70,

672 Marchand, D.E., 1977. The Cenozoic history of the San Joaquin Valley and the adjacent Sierra Nevada as inferred from the geology and soils of the eastern San Joaquin Valley. In: 
Singer, M.J., (Ed), Soil Development, Geomorphology, and Cenozoic History of the Northeastern San Joaquin Valley and Adjacent Areas, California. Guidebook for Joint Field Session, Soil Science Society of America and Geological Society of America, University of California Press, pp. 39-50.

Marchand, D.E., Allwardt, A., 1981. Late Cenozoic Stratigraphic Units, Northeastern San Lett. 51 (10), 607-610.

Molnar, P., 2004. Late Cenozoic increase in accumulation rates of terrestrial sediment: How Joaquin Valley, California, U.S. Geological Survey Bulletin 1470, United States Geological Survey Bulletin, p. 70. might climate change have affected erosion rates? Annu. Rev. Earth Planet. Sci. 32 6789.

Neimark, A.V., 1990. Thermodynamic Method for Calculating Surface Fractal Dimension. JETP

Neimark, A.V., 1992. A new approach to the determination of the surface fractal dimension of porous solids. Physica A 191 258-262.

Osmond, J.K., Ivanovich, M., 1992. Uranium-series mobilization and surface hydrology. In: Ivanovich, M., Harmon, R.S., (Eds), Uranium-series Disequilibrium: Applications to Earth, Marine, and Environmental Sciences, Clarendon Press, Oxford, pp. 259-288.

Pelt, E., Chabaux, F., Innocent, C., Navarre-Sitchler, A.K., Sak, P.B., Brantley, S.L., 2008. Uranium-thorium chronometry of weathering rinds: Rock alteration rate and paleoisotopic record of weathering fluids. Earth Planet. Sci. Lett. 276 (1-2), 98-105. 
Plater, A.J., Ivanovich, M., Dugdale, R.E., 1992. Uranium Series Disequilibrium in River Sediments and Waters - the Significance of Anomalous Activity Ratios. Appl. Geochem. 7 (2), 101-110.

Rama, Moore, W.S., 1984. Mechanism of Transport of U-Th Series Radioisotopes from Solids into Groundwater. Geochim. Cosmochim. Acta 48 (2), 395-399.

Raymo, M.E., Ruddiman, W.F., 1992. Tectonic Forcing of Late Cenozoic Climate. Nature 359 (6391), 117-122.

Sahouli, B., Blacher, S., Brouers, F., 1996. Fractal surface analysis by using nitrogen adsorption data: The case of the capillary condensation regime. Langmuir 12 (11), 2872-2874.

Sarna-Wojcicki, A.M., Pringle, M.S., Wijbrans, J., 2000. New Ar-40/Ar-39 age of the Bishop Tuff from multiple sites and sediment rate calibration for the Matuyama-Brunhes boundary. J. Geophys. Res.-Solid Earth 105 (B9), 21431-21443.

Semkow, T.M., Parekh, P.P., 1990. The Role of Radium Distribution and Porosity in Radon Emanation from Solids. Geophys. Res. Lett. 17 (6), 837-840.

Semkow, T.M., 1991. Fractal Model of Radon Emanation from Solids. Phys. Rev. Lett. 66 (23), 3012-3015.

Sharp, M., Gomez, B., 1986. Processes of Debris Comminution in the Glacial Environment and Implications for Quartz Sand-Grain Micromorphology. Sediment. Geol. 46 (1-2), 33-47.

Shirvington, P.J., 1983. Fixation of radionuclides in the $238 \mathrm{U}$ decay series in the vicinity of mineralized zones: 1. The Austatom Uranium Prospect, Northern Territory, Australia. Geochim. Cosmochim. Acta 47 (3), 403-412.

Sun, H.B., Semkow, T.M., 1998. Mobilization of thorium, radium and radon radionuclides in ground water by successive alpha-recoils. J. Hydrol. 205 (1-2), 126-136. 
Syvitski, J.P.M., Peckham, S.D., Hilberman, R., Mulder, T., 2003. Predicting the terrestrial flux of sediment to the global ocean: a planetary perspective. Sediment. Geol. 162 (1-2), 5-24.

Tessier, A., Campbell, P.G.C., Bisson, M., 1979. Sequential Extraction Procedure for the Speciation of Particulate Trace-Metals. Anal. Chem. 51 (7), 844-851.

Vigier, N., Bourdon, B., Turner, S., Allegre, C.J., 2001. Erosion timescales derived from Udecay series measurements in rivers. Earth Planet. Sci. Lett. 193 (3-4), 549-563.

Wahrhaftig, C., Birman, J.H., 1965. The Quaternary of the Pacific Mountain System in California. In: Wright, H.E., Frey, D.G., (Eds), The Quaternary of the United States, A Review Volume for the VII Congress of the International Association for Quaternary Research., Princeton University Press, Princeton, NJ, pp. 299-340.

Weissmann, G.S., Mount, J.F., Fogg, G.E., 2002. Glacially driven cycles in accumulation space and sequence stratigraphy of a stream-dominated alluvial fan, San Joaquin valley, California, USA. J. Sediment. Res. 72 (2), 240-251.

Weissmann, G.S., Bennett, G.L., Lansdale, A.L., 2005. Factors controlling sequence development on Quaternary fluvial fans, San Joaquin Basin, California, USA. In: Harvey, A.M., Mather, A.E., Stokes, M., (Eds), Alluvial Fans: Geomorphology, Sedimentology, Dynamics 251, Geological Society of London, pp. 169-186.

White, A.F., Peterson, M.L., 1990. Role of Reactive-Surface-Area Characterization in Geochemical Kinetic Models. In, Chemical Modeling of Aqueous Systems II, American Chemical Society Symposium Series 416, pp. 461-475.

Yin, Y.B., 1991. Adsorption-Isotherm on Fractally Porous Materials. Langmuir 7 (2), 216-217. 


\section{Figure captions}

744 Figure 1. Relationship of the uranium-series comminution age to other timescales of importance

745 in sedimentary processes. The start of the comminution age "clock" is particularly well-defined

746 for cases where the formation of fine-grained detrital clasts is rapid on a geologic timescale, such

747 as during glacial comminution of bedrock. The utility of subdividing the comminution age is

748 that these constituent timescales can also be determined from the comminution age, depending

749 on the availability of additional information. The comminution age is equal to the depositional

750 age in environments where the sediment transport + storage times are negligible. In settings

751 where the depositional age is independently known, the comminution age is equal to the

752 transport + storage time. Note that transport and storage of sediment particles can happen in

753 multiple environments en route from formation to deposition (e.g., hillslope and fluvial

754 environments in continental settings) - the transport + storage time includes the time spent in all

755 of these environments.

757 Figure 2. Shaded relief map of the area of the Kings River Fan. Thick black line, outline of the

758 Kings River drainage basin. Thin white line, outline of the glacially-derived Quaternary Kings

759 River Fan alluvial deposits (after Weissmann et al., 2002). Star denotes the location of USGS

760 sediment core B5, from which the samples in this study originate.

762 Figure 3. (a) Stratigraphic column of Kings River Fan core B5 showing depths of depositional

763 units and facies. After Weissmann et al. (2002), reprinted with permission from SEPM (Society

764 for Sedimentary Geology). (b) Age-depth relationship of the core sediments inferred from 
765 previous studies (see text). The samples investigated in this study were five glacial flour samples

766 (solid filled symbols) and one paleosol sample ( $\times$ symbol).

767

768 Figure 4. (a) Scanning electron microscopy (SEM) image of sample KRF-70 prior to sample

769 pretreatment. Note the large range of grain sizes and presence of nondetrital grain coatings. (b)

770 SEM image of the sample KRF-70 after sequential leaching pretreatment and microsieving to

771 isolate the 15 - $20 \mu \mathrm{m}$ size fraction. This shows angular, unweathered, and minimally-damaged

772 grains free of nondetrital coatings. The grains also occupy a narrow size range.

773

774 Figure 5. $\left({ }^{234} U /{ }^{238} U\right)$ activity ratios for sieved glacial flour samples (overbank and channel

775 facies) with well-constrained upper and lower bounds on grain diameter. As expected from the

776 comminution age model, these data show many characteristics consistent with having alpha

777 recoil as the dominant mechanism for ${ }^{234} \mathrm{U}$ loss from the grains. These characteristics include

$778 \quad\left({ }^{234} \mathrm{U} /{ }^{238} \mathrm{U}\right)$ values $<1$ that generally decrease with both age (depth) and grain size. The sample

779 at $21.34 \mathrm{~m}$ depth departs from the age trend; this can be related to the sample's unique grain size

780 distribution characteristics (see Section 5.4 text).

781

782 Figure 6. (a) $\left({ }^{234} \mathrm{U} /{ }^{238} \mathrm{U}\right)$ activity ratios for glacial flour samples with unconstrained bounds on

783 upper and/or lower grain diameter. (b) Grain size distribution characteristics for bulk, unsieved

784 glacial flour samples. $\mathrm{D}_{10}, \mathrm{D}_{50}$, and $\mathrm{D}_{90}$ denote the grain diameters at which $10 \%, 50 \%$, and $90 \%$

785 of the sample particles have a smaller diameter, respectively. The $\mathrm{U}$ isotopic behavior is in

786 accordance with the comminution age model and shows that the magnitude of the ${ }^{234} \mathrm{U}$ depletion

787 is strongly influenced by grain size as well as age. 
789 Figure 7. (a) Comminution ages calculated from the measured $\left({ }^{234} \mathrm{U} /{ }^{238} \mathrm{U}\right)$ values by assuming a 790 constant surface roughness factor $\left(\lambda_{r}\right)$ of 7 (symbols), as compared to the literature-derived age791 depth model (solid line). This simple approach yields calculated comminution ages that are of

792 the correct order of magnitude. However, grain size variations in $\lambda_{r}$ are not accounted for, which 793 is reflected in the scatter of calculated ages for different grain sizes at a given depth. (b) Surface

794 roughness factors required for the measured $\left({ }^{234} \mathrm{U} /{ }^{238} \mathrm{U}\right)$ values to correspond to the literature 795 model ages, as a function of grain diameter. Symbols correspond to those in Figure 3b. a, 796 Riverbank Formation; b-e, Turlock Lake Formation. Calculations assume a shape factor of $K=$ 7976 and no internal surface area. $\lambda_{r}$ is a clear function of grain size for the KRF sediments.

799 Figure 8. Comminution ages calculated using the measured $\left({ }^{234} \mathrm{U} /{ }^{238} \mathrm{U}\right)$ values and a set of $f_{\alpha}$ 800 values derived from the $43.80 \mathrm{~m}$ sample (symbols), as compared to the literature-derived age801 depth model (solid line). This approach does not take into account possible increases in $f_{\alpha}$ with 802 age, which would shift the comminution ages for the younger samples to larger values, providing 803 a better match to the literature age-depth curve. 
Click here to download Figure: LeeEtal_Fig1.eps

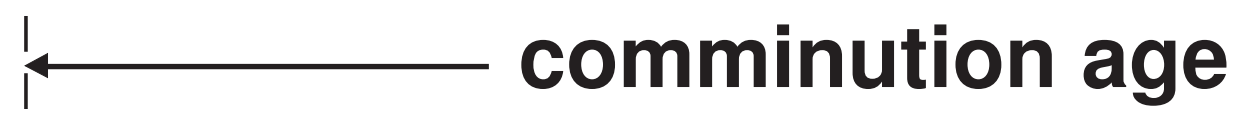

comminution age

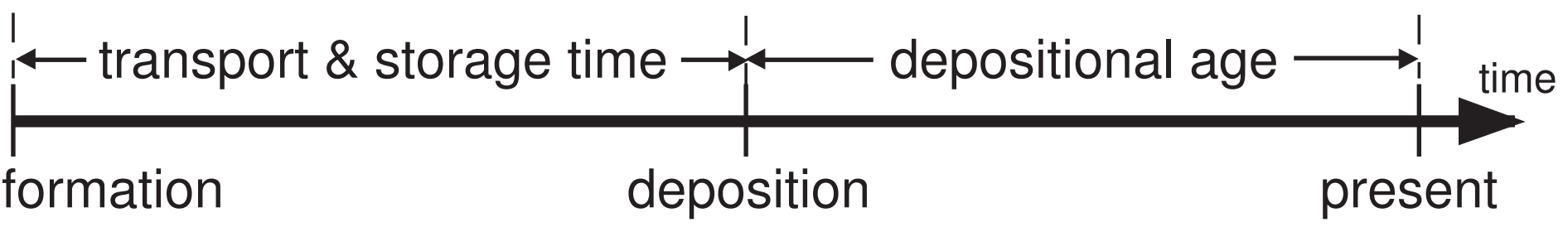

particle formation

deposition

present

(reduction below

$\sim 50 \mu \mathrm{m}$ grain diameter) 


\section{Figure 2}

Click here to download Figure: LeeEtal_Fig2.eps

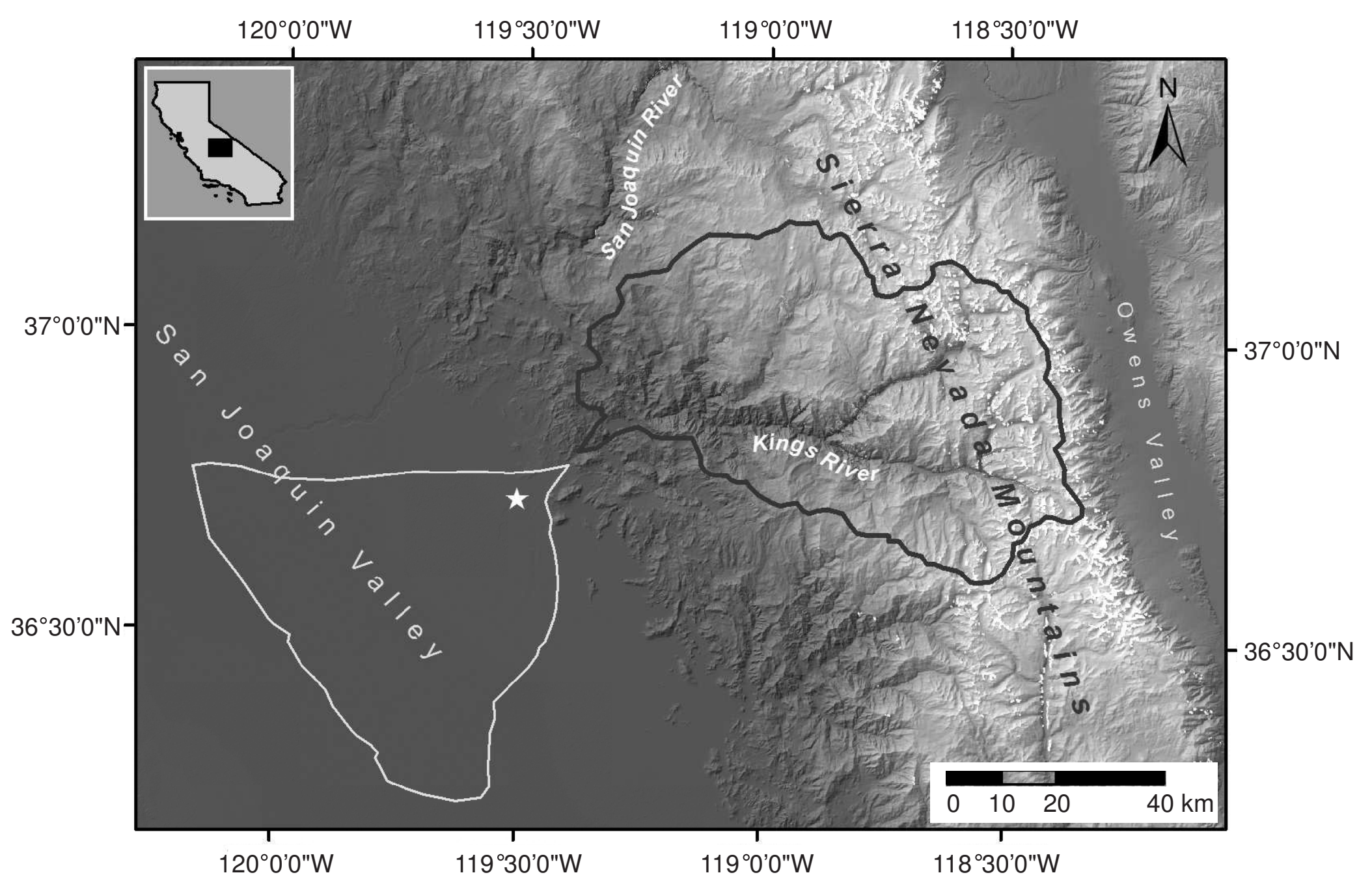




\section{Figure 3}

Click here to download Figure: LeeEtal_fig3.xIs

a

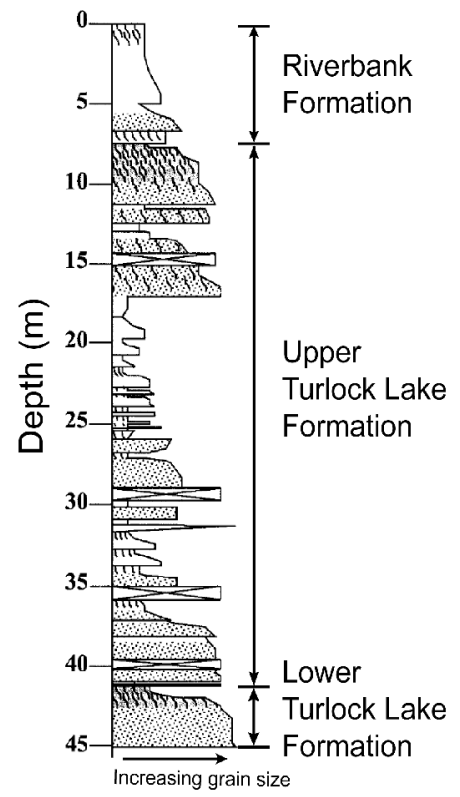

channel facies assemblage $\square$ overbank facies assemblage [1] moderately mature paleosol Di] paleosol, less mature b

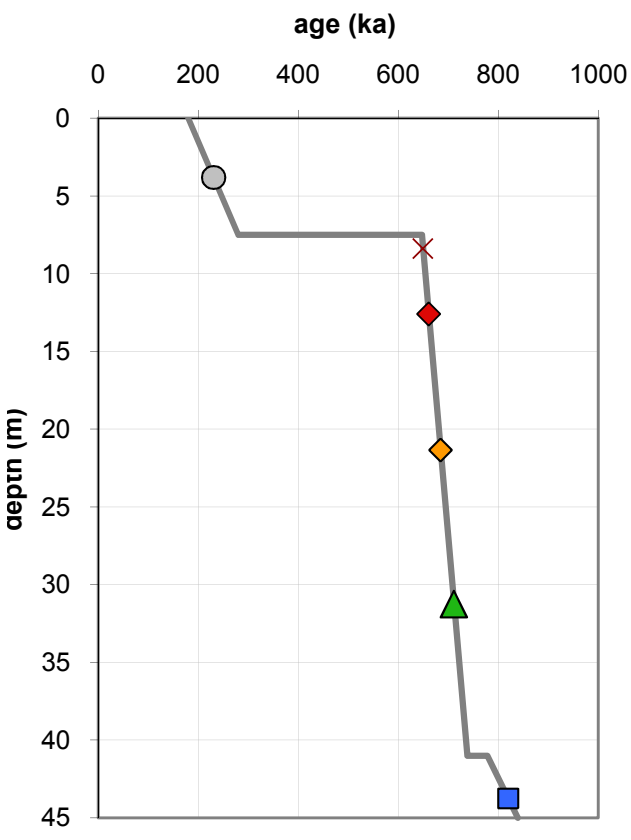



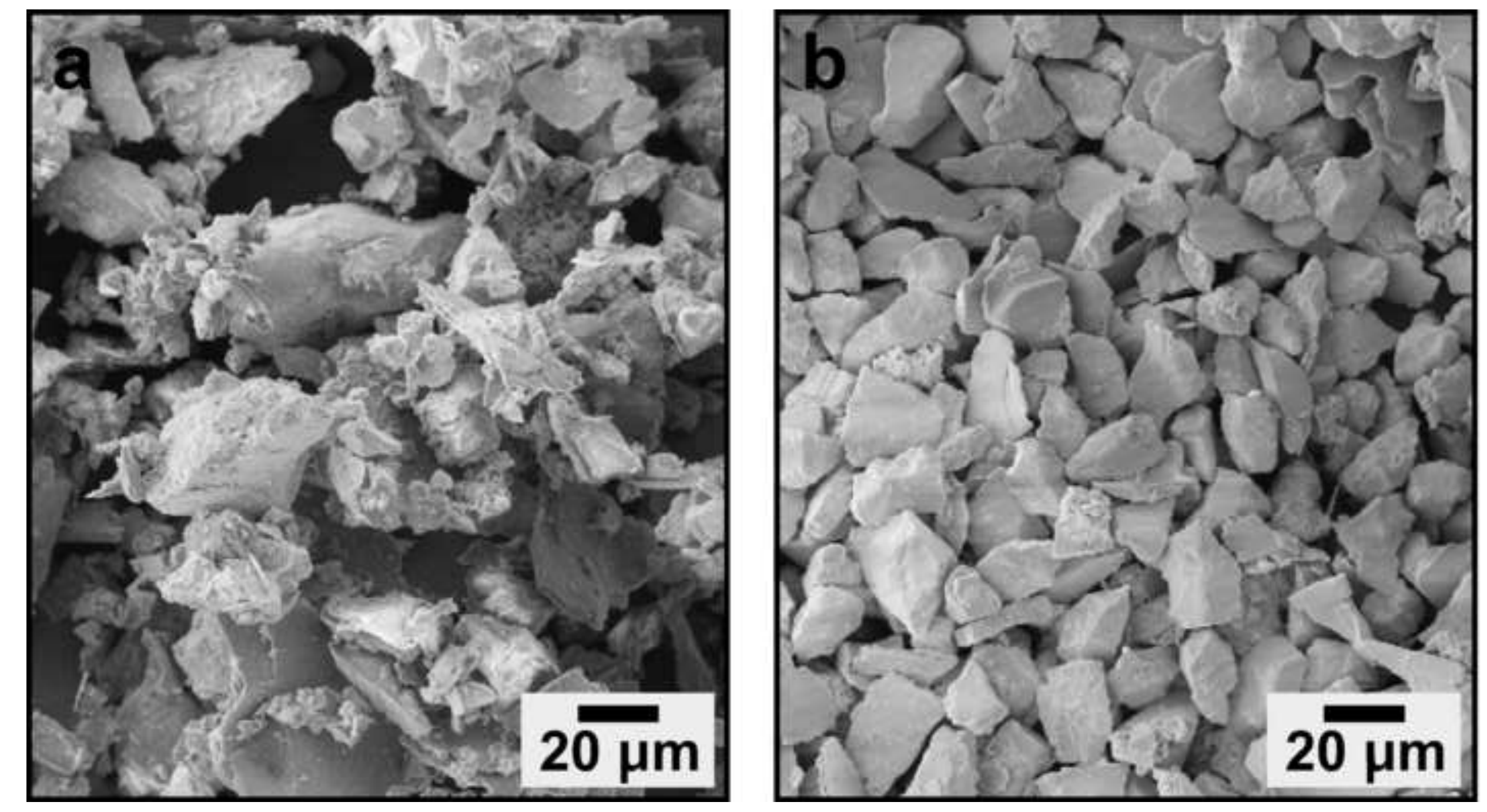
Figure 5
Click here to download Figure: LeeEtal_Fig5.xls
\[ \left({ }^{234} \mathrm{U} / 238 \mathrm{U}\right) \]

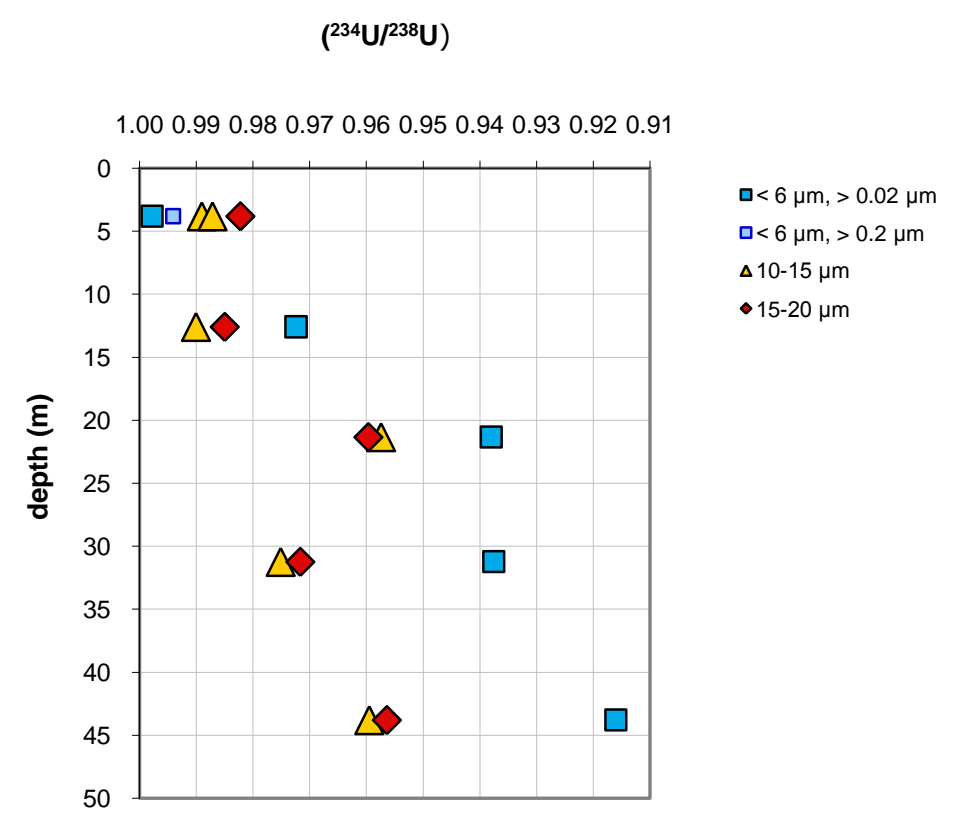


Click here to download Figure: LeeEtal_Fig6.xls

a

( $\left.{ }^{234} \mathrm{U} /{ }^{238} \mathrm{U}\right)$

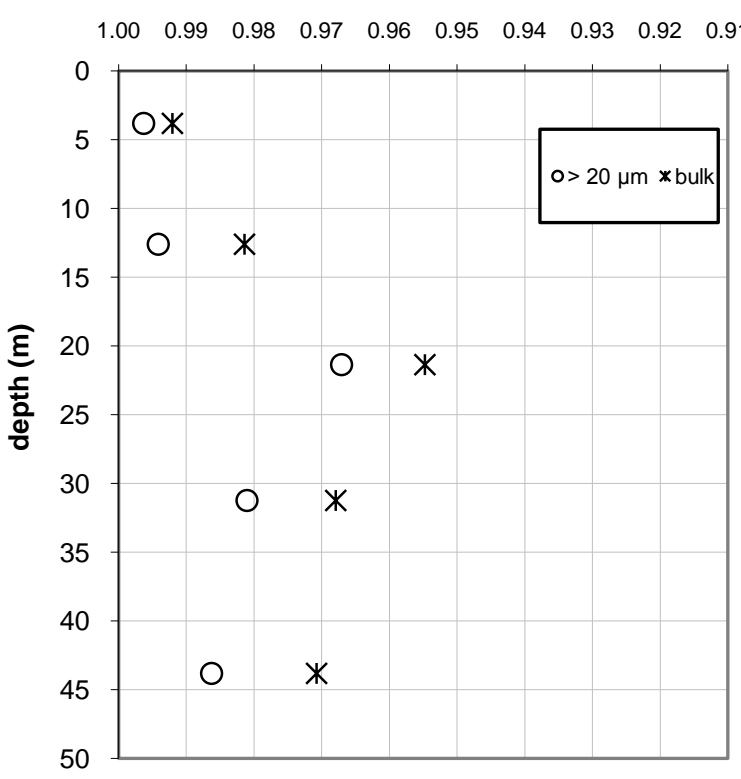

b

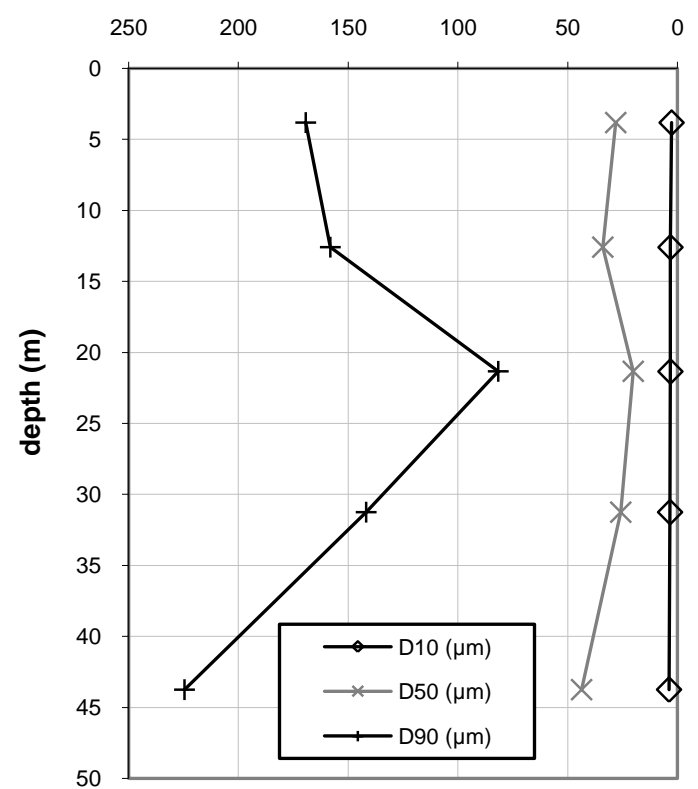




\section{Click here to download Figure: LeeEtal_Fig7.xls}

a

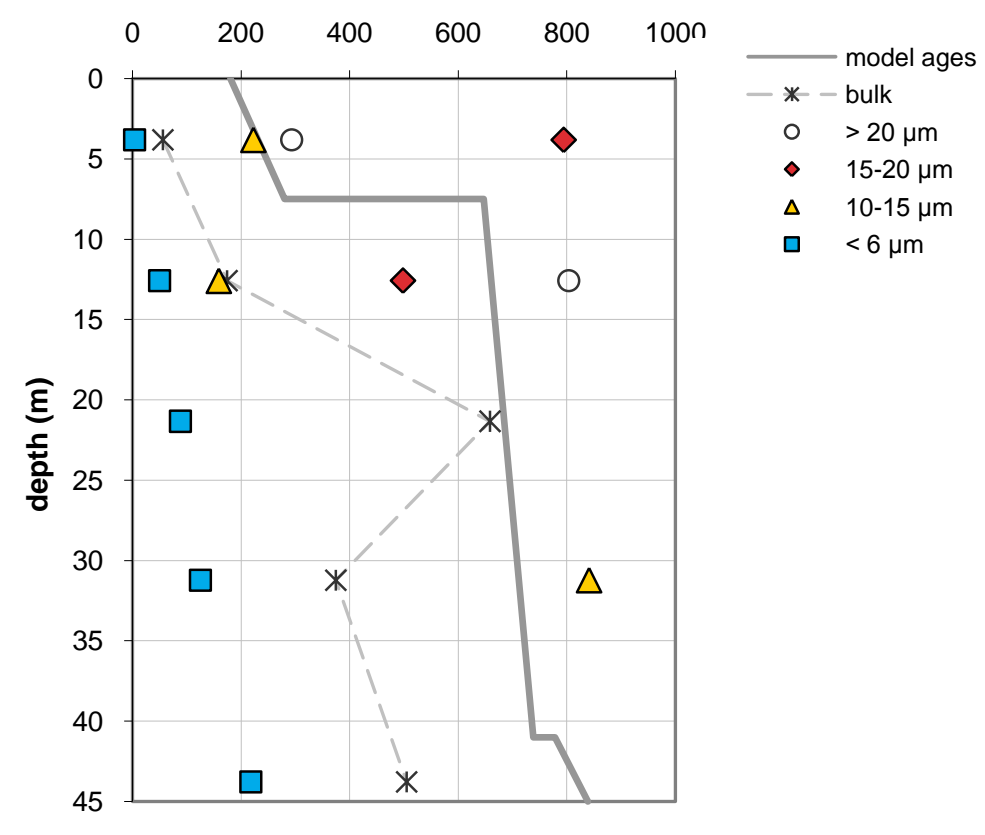

b

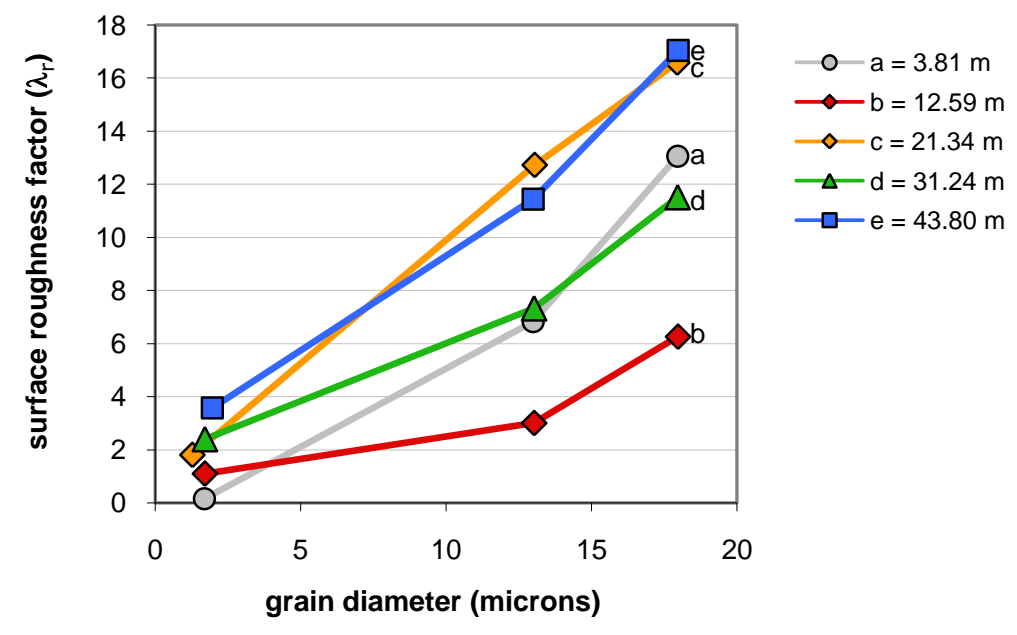


Figure 8
Click here to download Figure: LeeEtal_Fig8.xIs

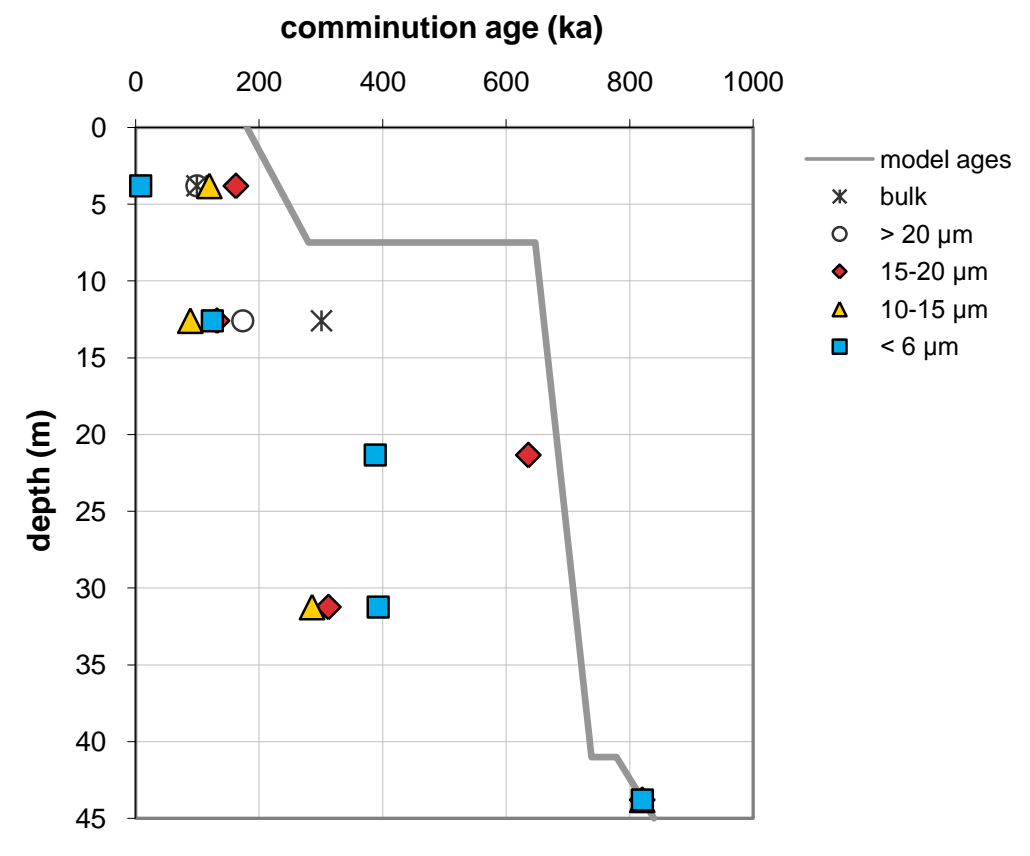


Click here to download Table: LeeEtal_Revised_Table1.doc

TABLE 1. Kings River Fan core B5, isotopic and grain size analyses ${ }^{\text {a,b }}$

\begin{tabular}{|c|c|c|c|c|c|c|c|c|c|c|}
\hline \multirow{3}{*}{$\begin{array}{l}\text { Depth } \\
\text { (m) }\end{array}$} & \multirow{3}{*}{$\begin{array}{l}\text { Depositional } \\
\text { facies }\end{array}$} & \multirow{3}{*}{$\begin{array}{c}\text { Depositional } \\
\text { age }^{c}(\mathrm{ka})\end{array}$} & \multirow{3}{*}{$\begin{array}{c}D_{50} \\
(\mu \mathrm{m})\end{array}$} & \multirow[t]{3}{*}{$\varepsilon_{\mathrm{Nd}}$} & \multirow[t]{3}{*}{${ }^{87} \mathrm{Sr} /{ }^{86} \mathrm{Sr}$} & & \multicolumn{4}{|c|}{$\left({ }^{234} \mathrm{U} /{ }^{238} \mathrm{U}\right)$ activity ratios ${ }^{1}$} \\
\hline & & & & & & \multirow[t]{2}{*}{ Bulk sample } & \multicolumn{4}{|c|}{ Grain diameters of sieved samples } \\
\hline & & & & & & & $>20 \mu \mathrm{m}$ & $15-20 \mu \mathrm{m}$ & $10-15 \mu \mathrm{m}$ & $<6 \mu \mathrm{m}$ \\
\hline 3.81 & overbank & 230 & 28 & $-5.80(10)$ & $0.708132(10)$ & $0.9920(29)$ & $0.9963(11)$ & $0.9822(12)$ & $0.9872(10)$ & $0.9978(12)$ \\
\hline 8.38 & paleosol & 650 & 201 & $+3.69(10)$ & $0.704803(13)$ & $1.0843(32)$ & $1.0310(15)$ & -- & 1.1254 (39) & $1.1569(16)$ \\
\hline 12.59 & overbank & 660 & 34 & $-4.77(12)$ & $0.707914(28)$ & $0.9814(28)$ & $0.9941(15)$ & $0.9850(13)$ & $0.9901(13)$ & $0.9380(10)$ \\
\hline 21.34 & overbank & 685 & 20 & $-5.10(14)$ & $0.708074(13)$ & $0.9547(21)$ & $0.9670(15)$ & $0.9597(14)$ & 0.9574 (17) & $0.9724(13)$ \\
\hline 31.24 & overbank & 710 & 26 & $-5.02(14)$ & $0.708167(10)$ & $0.9679(30)$ & $0.9810(13)$ & $0.9717(12)$ & $0.9751(12)$ & $0.9376(11)$ \\
\hline 43.80 & channel & 820 & 44 & $-5.58(14)$ & $0.708364(21)$ & $0.9707(15)$ & $0.9863(14)$ & $0.9564(16)$ & $0.9595(49)$ & $0.9161(14)$ \\
\hline
\end{tabular}

${ }^{a}$ Numbers in parentheses denote uncertainties in the last two digits of the reported value. Uncertainties on $\left({ }^{234} \mathrm{U} /{ }^{238} \mathrm{U}\right)$ values are $95 \%$ confidence intervals.

${ }^{\mathrm{b}} \mathrm{D}_{50}, \mathrm{Nd}$ isotopes, and $\mathrm{Sr}$ isotopes are measured on bulk samples.

${ }^{\mathrm{c}}$ Depositional age-depth model determined from Marchant \& Allwardt (1981) and Lettis (1988). 
TABLE 2. Summary of methods to determine the recoil loss factor $f_{\alpha}$ for ${ }^{238} \mathrm{U}-{ }^{234} \mathrm{U}$ decay

\begin{tabular}{|c|c|c|c|c|}
\hline & Approach & Equation(s) & & Comments \\
\hline 1) & $\begin{array}{l}\text { Sieve samples to constrain grain diameter } d \text {, apply an } \\
\text { appropriate surface roughness factor } \lambda_{r} \text {. }\end{array}$ & $f_{\alpha}=\frac{L K}{4 d} \lambda_{r}$ & (Eqn. 4) & $\begin{array}{l}\lambda_{r} \text { may vary as a function of both grain size } \\
\text { and sample age. } \lambda_{r} \text { must also describe surface } \\
\text { roughness at the lengthscale of alpha recoil. }\end{array}$ \\
\hline 2) & $\begin{array}{l}\text { Measure the }\left({ }^{234} \mathrm{U} /{ }^{238} \mathrm{U}\right) \text { activity ratio of a sample old } \\
\text { enough to be at steady state with respect to the }{ }^{234} \mathrm{U} \\
\text { and }{ }^{238} \mathrm{U} \text { isotopes }(>\sim 1 \mathrm{Ma})^{\mathrm{a}} \text {. }\end{array}$ & $f_{\alpha}=1-\left(\frac{{ }^{234} U}{{ }^{238} U}\right)$ & & $\begin{array}{l}\text { Old samples may have } f_{\alpha} \text { values that have } \\
\text { increased with age, perhaps due to weathering. }\end{array}$ \\
\hline 3) & $\begin{array}{l}\text { Measure the }\left({ }^{226} \mathrm{Ra}^{230} \mathrm{Th}\right) \text { activity ratio from a sample } \\
\text { at steady state with respect to the }{ }^{230} \mathrm{Th} \text { and }{ }^{226} \mathrm{Ra} \\
\text { isotopes }(>10 \mathrm{ka}){ }^{\mathrm{a}} \text {. }\end{array}$ & $f_{\alpha}=\left(\frac{34}{37}\right)\left[1-\left(\frac{{ }^{226} R a}{{ }^{230} T h}\right)\right]$ & & $\begin{array}{l}\text { The (34/37) prefactor corrects for the slight } \\
\text { difference in recoil distance for }{ }^{234} \mathrm{U} \text { as } \\
\text { compared to }{ }^{230} \mathrm{Th} \text {. }\end{array}$ \\
\hline 4) & $\begin{array}{l}\text { Directly obtain total surface area }\left(S_{\text {tot }}\right) \text { (e.g., measured } \\
\text { from BET gas adsorption measuremts). }\end{array}$ & $f_{\alpha}=\frac{1}{4} L \cdot S_{t o t} \cdot \rho$ & (Eqn. 2) & $\begin{array}{l}\text { If } S_{\text {to }} \text { is measured by BET gas adsorption, this } \\
\text { approach is applicable only to solids with } \\
\text { characteristic surface roughness lengthscales } \\
\text { that are approximately equal to or greater than } \\
\text { the alpha recoil distance (i.e., meso- and } \\
\text { macro-porous solids). }\end{array}$ \\
\hline \multirow[t]{4}{*}{ 5) } & $\begin{array}{l}\text { Obtain surface area from BET gas adsorption } \\
\text { measurements }\left(S_{B E T}\right) \text {, translate to recoil-relevant } \\
\text { lengthscales with a model for surface roughness. } \\
\text { Example: fractal model for surface roughness }{ }^{\mathrm{b}} \text {. }\end{array}$ & $f_{\alpha}=\frac{1}{4}\left[\frac{2^{D-1}}{4-D}\left(\frac{a}{L}\right)^{D-2}\right] L \cdot S_{B E T} \cdot \rho$ & (Eqn. 6) & $\begin{array}{l}\text { Need to independently obtain fractal } \\
\text { dimension } D \text { that describes roughness at the } \\
\text { lengthscale of alpha recoil. }\end{array}$ \\
\hline & $\begin{array}{l}\text { Determining } D \text { from gas adsorption measurements }{ }^{\mathrm{c}} \text { : } \\
\text { 5a) Frenkel-Halsey-Hill }\end{array}$ & $N \propto\left[\ln \left(P_{0} / P\right)\right]^{D-3}$ & & \\
\hline & 5b) Neimark-Kiselev & $S_{\mathrm{lg}}=K a_{c}^{2-D}$ & & \\
\hline & 5c) Pore size distribution & $J(r) \propto r^{2-D}$ & & \\
\hline
\end{tabular}

${ }^{a}$ DePaolo et al., 2006

${ }^{\mathrm{b}}$ Semkow, 1990

' Jaroniec, 1995; Lowell et al., 2004 

Supplementary material for on-line publication only
Click here to download Supplementary material for o

Click here to download Supplementary material for on-line publication only: LeeEtal_KRF_Supplnfo-Revised_FINAL.doc

line publication only: LeeEtal_KRF_Supplnfo-Revised_FINAL.doc (1) 西 (1) . . . .

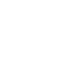
. . 